\title{
FGF-1 Triggers Pannexin-1 Hemichannel Opening in Spinal Astrocytes of Rodents and Promotes Inflammatory Responses in Acute Spinal Cord Slices
}

\author{
Juan Mauricio Garré, ${ }^{1,2}$ Guang Yang, ${ }^{1}$-Feliksas F. Bukauskas, ${ }^{2,3}$ and Michael V. L. Bennett ${ }^{2}$ \\ ${ }^{1}$ Department of Anesthesiology, Perioperative Care and Pain Medicine, New York University School of Medicine, New York, New York 10016, ${ }^{2}$ Dominick P. \\ Purpura, Department of Neuroscience, Albert Einstein College of Medicine, Bronx, New York 10461, and 3Institute of Cardiology, Lithuanian University of \\ Health Sciences, Kaunas LT-50161, Lithuania
}

We show here that the growth factor FGF-1 is proinflammatory in the spinal cord and explore the inflammatory mechanisms. FGF-1 applied to rat spinal astrocytes in culture initiates calcium signaling and induces secretion of ATP that within minutes increases membrane permeability to ethidium $\left(\mathrm{Etd}^{+}\right)$and $\mathrm{Ca}^{2+}$ by activating $\mathrm{P} 2 \mathrm{X}_{7}$ receptors $\left(\mathrm{P} 2 \mathrm{X}_{7} \mathrm{Rs}\right)$ that open pannexin hemichannels $(\mathrm{Px} 1 \mathrm{HCs})$ that release further ATP; by $7 \mathrm{~h}$ treatment, connexin 43 hemichannels (Cx43 HCs) are also opened. In acute mouse spinal cord slices ex vivo, we found that FGF-1 treatment for $1 \mathrm{~h}$ increases the percentage of GFAP-positive astrocytes that show enhanced Px1 HC-mediated Etd ${ }^{+}$ uptake. This response to FGF-1 was not observed in astrocytes in slices of cerebral cortex. FGF-1-induced dye uptake by astrocytes is prevented by BAPTA-AM or a phospholipase C (PLC) inhibitor. Furthermore, in spinal cord slices, $\mathrm{P}_{2} \mathrm{X}_{7} \mathrm{R}$ antagonists (BBG and A740003) and Px1 HC blockers $\left({ }^{10} \mathrm{Panx} 1\right.$ and carbenoxolone) prevent the increase in $\mathrm{Etd}^{+}$uptake by astrocytes, whereas Gap 19, a selective $\mathrm{Cx} 43 \mathrm{HC}$ blocker, has no effect on dye uptake at this time. Microglia are not required for the increase in $\mathrm{Etd}^{+}$uptake by astrocytes induced by FGF-1, although they are activated by FGF-1 treatment. The morphological signs of microglia activation are inhibited by $\mathrm{P} 2 \mathrm{X}_{7} \mathrm{R}$ antagonists and ${ }^{10} \mathrm{Panx} 1$ and are associated with elevated levels of proinflammatory cytokines in cord slices treated with FGF-1. The FGF-1 initiated cascade may play an important role in spinal cord inflammation in vivo.

Key words: astrocyte; fibroblast growth factor; glia; inflammation; microglia; spinal cord

Significance Statement

We find that FGF-1 elevates $\left[\mathrm{Ca}^{2+}\right]_{\mathrm{i}}$ in spinal astrocytes, which causes vesicular release of ATP and activation of P2X $\mathrm{X}_{7} \mathrm{Rs}$ to trigger opening of Px1 HCs, which release further ATP. This regenerative response occurs in astrocyte cultures and in acute spinal cord slices. In the latter, FGF-1 application promotes the activation of microglia and increases the production of proinflammatory cytokines through mechanisms depending on P2X7 receptors and Px1 HCs. This proinflammatory microenvironment may favor recruitment of leukocytes into the spinal cord and impacts negatively on neuronal structure and function in vivo. Any step in these processes provides a potential therapeutic target for treatment of secondary damage in various spinal cord pathologies.

\section{Introduction}

Fibroblast growth factor-1 (FGF-1) and FGF receptors are widely expressed in the CNS (Reuss and von Bohlen und Halbach,

Received Nov. 20, 2015; revised March 12, 2016; accepted March 16, 2016.

Author contributions: J.M.G., G.Y., F.F.B., and M.V.L.B. designed research; J.M.G. performed research; J.M.G., G.Y., F.F.B., and M.V.L.B. analyzed data; J.M.G., G.Y., F.F.B., and M.V.L.B. wrote the paper.

This work was supported by National Institutes of Health Grants NS45287 and NS55363 to M.V.L.B. and NS072238 to F.F.B., National Institutes of Health Grants GM107469 and AG048410 to G.Y., and Research Council of Lithuania MIP-76/2015 to F.F.B. We thank Dr. Angela Bukauskiene, Fabrizio Pontarelli, and Dr. Helmuth Sanchez (Department of Neuroscience, Albert Einstein College of Medicine, Bronx, New York) for technical assistance with the cell cultures; and members of Maarten Reith's laboratory (Department of Psychiatry, New York University, New York) and Dr. Esperanza Recio-Pinto and Dr. Alexandra Sideris in Thomas Blanck's laboratory (Department of Anesthesiology, Perioperative Care and Pain Medicine, New York University, New York) for assistance in the preparation of spinal cord slices.
2003). In cerebral cortex, FGF signaling maintains astrocytes in an unreactive state and reduces activation after a stab wound (Kang et al., 2014). In contrast, FGF-2, which also acts on FGF receptors, is associated with inflammatory changes in spinal cord and neuropathic pain (Ji et al., 2013). Furthermore, FGF-1 can

\footnotetext{
The authors declare no competing financial interests.
}

Correspondence should be addressed to either of the following: Dr. Juan Mauricio Garré, Department of Anesthesiology, Perioperative Care and Pain Medicine, New York University School of Medicine, 450 East 29th Street, Lab-843F, New York, NY 10016, E-mail: Juan.GarreCastro@nyumc.org or jmgarre@gmail.com; or Dr. Michael V.L. Bennett, Dominick P. Purpura, Department of Neuroscience, Albert Einstein College of Medicine, 1300 Morris Park Ave., Room 718, Bronx, NY 10461. E-mail: michael.bennett@einstein.yu.edu.

DOI:10.1523/JNEUROSCI.4195-15.2016

Copyright $\odot 2016$ the authors $\quad 0270-6474 / 16 / 364785-17 \$ 15.00 / 0$ 
activate spinal cord astrocytes in culture and increase the production of neurotoxic factors (Cassina et al., 2005). Also, FGF-1 enhances cytokine production in human cortical astrocytes and microglia primed with interferon $\gamma($ IFN $\gamma)$ or lipopolysaccharide (LPS) + IFN $\gamma$ (Lee et al., 2011). Whether FGF-1 is proinflammatory in spinal cord by activating astrocytes or microglia is unknown.

Astrocytes show regenerative responses that involve increased cytoplasmic free calcium, $\left[\mathrm{Ca}^{2+}\right]_{\mathrm{i}}$ (Cornell-Bell et al., 1990; Nedergaard, 1994; Hassinger et al., 1996; Guthrie et al., 1999). Rises in $\left[\mathrm{Ca}^{2+}\right]_{i}$ can be initiated by external ligands, such as ATP, that open $\mathrm{Ca}^{2+}$-permeable channels in the surface membrane and by $\mathrm{Ca}^{2+}$-evoked and $\mathrm{IP}_{3} \mathrm{R}$-mediated $\mathrm{Ca}^{2+}$ release from intracellular stores. Gap junctions allow $\mathrm{IP}_{3}$ to diffuse between contacting astrocytes, thereby propagating calcium waves by an intracellular path (Charles et al., 1991; Venance et al., 1997). Both of these mechanisms can contribute to propagation of calcium waves in astrocytes (Scemes and Giaume, 2006). There is accumulating evidence that diverse compartmentalized $\mathrm{Ca}^{2+}$ signals in astrocytes underlie different physiological and pathological processes in vitro and in vivo (Khakh and Sofroniew, 2015).

Connexin-based gap junction (GJ) channels are formed by two hemichannels (HCs), one contributed by each apposed cell. HCs in surface membrane, but not docked with an HC in an apposed membrane, may open, particularly in media containing a low concentration of divalent cations (Contreras et al., 2002). In vertebrates, endogenous pannexins also form HCs but have not been shown to form gap junctions, although exogenous pannexins appear do so in Xenopus oocytes, HeLa cells, and two other cell lines (Bruzzone et al., 2003, 2005; Lai et al., 2007; Sahu et al., 2014). Opening of $\mathrm{Cx} 43 \mathrm{HCs}$ can increase $\left[\mathrm{Ca}^{2+}\right]_{\mathrm{i}}$ in astrocytes by allowing calcium influx (Bennett et al., 2003) or by allowing release of ATP (Kang et al., 2008), which activates purinergic receptors that in turn open pannexin 1 (Px1) HCs (Locovei et al., 2006) that permit further $\mathrm{Ca}^{2+}$ entry and ATP efflux. Spinal astrocytes can form HCs of $\mathrm{Cx} 43$ or Px1. Cultured spinal astrocytes treated with FGF-1 release ATP from vesicles, which activates $\mathrm{P} 2 \mathrm{X}_{7}$ Rs that open $\mathrm{Px} 1 \mathrm{HCs}$ within $2 \mathrm{~h}$ and $\mathrm{Cx} 43 \mathrm{HCs}$ within $7 \mathrm{~h}$ (Garré et al., 2010). Furthermore, FGFRs activate phospholipase $\mathrm{C} \gamma(\mathrm{PLC} \gamma)$, which hydrolyzes PIP2 to form $\mathrm{IP}_{3}$ that enhances release of $\mathrm{Ca}^{2+}$ from ER (Reuss and von Bohlen und Halbach, 2003; Bunney et al., 2012). Thus, PLC $\gamma$ is a potential link between activation of FGF receptors in surface membrane and mobilization of $\mathrm{Ca}^{2+}$ from intracellular stores, a process leading to vesicular ATP release, activation of $\mathrm{P} 2 \mathrm{X}_{7} \mathrm{Rs}$, opening of Px1 HCs, and self-sustaining ATP release. FGF-1-induced release of ATP from spinal astrocytes may stimulate microglia because these cells continuously monitor extracellular space for rise in ATP levels and CNS damage (Davalos et al., 2005).

We report here that, in cultured spinal astrocytes, FGF-1 application rapidly increases permeability to $\mathrm{Etd}^{+}$through activation of $\mathrm{P}_{2} \mathrm{X}_{7} \mathrm{Rs}$ and Px1 HCs, processes that depend on PLC activation and rise in $\left[\mathrm{Ca}^{2+}\right]_{\mathrm{i}}$. FGF-1 also activates $\mathrm{P} 2 \mathrm{X}_{7} \mathrm{Rs}$ and Px1 HCs of astrocytes in acute slices of spinal cord, but not of cortex. In spinal cord slices depleted of microglia, FGF-1 still activates $\mathrm{P} 2 \mathrm{X}_{7} \mathrm{Rs}$ and opens $\mathrm{Px} 1 \mathrm{HCs}$ of astrocytes, suggesting direct FGF-1 action. These responses of spinal astrocytes to FGF-1 in spinal cord sustain ATP release and favor a proinflammatory environment that promotes microglial activation and increase in cytokine production. The cascade described here in vitro may play an important role in spinal cord inflammation and neurodegeneration in vivo.

\section{Materials and Methods}

Animals. Rat pups (postnatal day 1) or anesthetized 1-month-old mice of either sex were decapitated before the removal of spinal cord and cerebral cortex for culture or slice preparation. Experimental procedures performed in cell cultures were approved by the Institutional Animal Care and Use Committee of the Albert Einstein College of Medicine (protocol \#20110809) and for adult mouse tissue collection were approved by the Institutional Animal Care and Use Committee of the New York University School of Medicine (protocol \#140807-01).

Materials. Culture medium and serum were from Gibco BRL. FGF-1 and all other reagents were from Sigma unless otherwise specified.

Cell cultures. Astrocytes from spinal cords of 1-d-old rat pups (P1) were prepared and cultured as described by Cassina et al. (2005). Briefly, rat spinal cords were removed from $\mathrm{P} 1$ pups, and tissue was dissociated by treating it for $25 \mathrm{~min}$ with $0.001 \%$ tripsin- $0.0002 \%$ EDTA solution in PBS (stock: $0.25 \%$ trypsin and 0.1\% EDTA, Invitrogen) and subsequent mechanical dissociation in maintenance medium composed of DMEM supplemented with $10 \%$ FBS, penicillin $(100 \mathrm{IU} / \mathrm{ml})$, and streptomycin $(100 \mu \mathrm{g} / \mathrm{ml})$. For mouse spinal cords, trypsin was not added and tissue was dissociated mechanically in maintenance medium. Cells were plated (at $2.0 \times 10^{4} \mathrm{cells} / \mathrm{cm}^{2}$ ) on $12 \mathrm{~mm}$ glass coverslips or on $60 \mathrm{~mm}$ plastic culture dishes and kept in DMEM supplemented with 10\% FBS, penicillin $(100 \mathrm{IU} / \mathrm{ml})$, and streptomycin $(100 \mu \mathrm{g} / \mathrm{ml})$. Cultures were grown at $37^{\circ} \mathrm{C}$ in a humidified atmosphere of $5 \% \mathrm{CO}_{2}$. Astrocyte cultures in confluent monolayers were $>98 \%$ pure as determined by their GFAP immunoreactivity, and there were no cells positive for Cd11b, a marker for cells of myeloid lineage used to stain microglial cells in the CNS.

HeLa cells stably expressing either Cx43-CFP or Px1-YFP were seeded together with HeLa parental cells $2 \mathrm{~d}$ before experiments. Mixed cultures were treated with ${ }^{10} \mathrm{Panx} 1(100 \mu \mathrm{M})$ or Gap19 $(100 \mu \mathrm{M})$ for $0.5-1 \mathrm{~h}$. Both blockers were also maintained during $\mathrm{Etd}^{+}$uptake recordings.

Drugs and solutions. Solution compositions (in $\mathrm{mm}$ ) are as follows: Tyrode's, $\mathrm{NaCl}$ (140), $\mathrm{KCl}(4), \mathrm{CaCl}_{2}$ (1.8), $\mathrm{MgCl}_{2}$ (1), glucose (5), $\mathrm{Na}$ pyruvate (2), HEPES (5), pH 7.4; Hanks, $\mathrm{NaCl}$ (137), $\mathrm{KCl}$ (5), $\mathrm{CaCl}_{2}$ (1.8), $\mathrm{MgCl}_{2}$ (0.95), $\mathrm{KH}_{2} \mathrm{PO}_{4}(0.4), \mathrm{MgSO}_{4}(0.4), \mathrm{NaHCO}_{3}$ (4), $\mathrm{NaH}_{2} \mathrm{PO}_{4}(0.3)$, glucose (5), $\mathrm{pH}$ 7.4. Artificial CSF (ACSF) used for slices (in mM) as follows: $\mathrm{NaCl}(119), \mathrm{KCl}(2.5)$, D-glucose (11), $\mathrm{NaH}_{2} \mathrm{PO}_{4}$ (1), $\mathrm{CaCl}_{2}$ (2.5), $\mathrm{MgCl}_{2}$ (1.3), $\mathrm{NaHCO}_{3}$ (26). Hanks solution and ACSF were bubbled with $\mathrm{O}_{2}(95 \%), \mathrm{CO}_{2}(5 \%)$.

The ethidium bromide (EtdBr) used for dye uptake experiments was prepared from a $1 \mathrm{~mm}$ stock solution and applied to cells at 1-10 $\mu \mathrm{M}$. Heptanol (0.4-1 mM), carbenoxolone $(200 \mu \mathrm{M})$, Brillant Blue G (BBG; $1-100 \mu \mathrm{M})$, and Reactive Blue $2(\mathrm{RB} 2 ; 1-100 \mu \mathrm{M})$ were applied to the cells

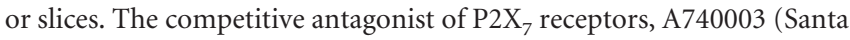
Cruz Biotechnology), was dissolved in DMSO and diluted to the final concentration of 1-100 $\mu \mathrm{M}$. Apyrase (APY; Sigma) from potato was dissolved in PBS or ACSF at $2 \mathrm{U} / \mathrm{ml}$ and diluted to the final concentration of $2 \mathrm{mU} / \mathrm{ml}$. The PLC blocker, U73122 (Sigma), was dissolved in DMSO as a $1 \mathrm{~mm}$ stock solution. The same procedure was used for preparing a stock solution of U73343. For experiments in spinal cord slices, we also used the selective blockers of Px1 HC and Cx43 HCs, ${ }^{10} \mathrm{Panx} 1$ and Gap 19 (Tocris Bioscience) peptides, respectively. These blockers or their scrambled sequences were dissolved in ACSF at $1 \mathrm{~mm}$ stock solution and diluted to a final concentration of $100 \mu \mathrm{M}$.

Cell treatments with FGF-1. Because heparin sulfate proteoglycans stabilize the interaction of FGFs with FGFRs, FGF-1 (Sigma) was prepared as a $10 \mu \mathrm{g} / \mathrm{ml}$ stock solution in PBS and then diluted $10 \times$ in $5000 \mathrm{IU} / \mathrm{ml}$ heparin (Brown et al., 1995). FGF-1 stock solutions were freshly prepared $<1$ h before each experiment. For treatments $<1 \mathrm{~h}$, confluent astrocyte cultures were washed 3 times in Tyrode's solution containing $5 \mu \mathrm{M} \mathrm{Etd}{ }^{+}$ and control vehicle (heparin $50 \mathrm{IU} / \mathrm{ml}$ ). Then, cells were imaged for 5 min to measure the basal $\mathrm{Etd}^{+}$uptake rate. Thereafter, FGF-1 $(10 \mathrm{ng} / \mathrm{ml})$ and heparin $(50 \mathrm{IU} / \mathrm{ml})$ were applied in Tyrode's solution. For FGF-1 treatments $>1 \mathrm{~h}$, the maintenance medium was replaced by DMEM containing $1 \%$ horse serum. Under these conditions, cells were incubated with FGF-1 for different time periods at $37^{\circ} \mathrm{C}$ in a humidified atmosphere of $5 \% \mathrm{CO}_{2}$. Heparin alone had no effect on dye uptake (evaluated as fluorescence intensity in arbitrary units [AU]) of astrocytes 
maintained under basal conditions (i.e., incubated in Tyrode's solution or DMEM with $1 \%$ FBS; $p>0.05$ ).

Ethidium permeability assays. Ethidium uptake was measured by fluorescence of $\mathrm{Etd}^{+}$when it bound to double-stranded oligonucleotides in cells cultured under control conditions and after treatment with FGF-1. For time course measurements of $\mathrm{Etd}^{+}$uptake, control and treated cultures were washed with Tyrode's solution containing $5 \mu \mathrm{M}$ EtdBr at room temperature for 3-5 $\mathrm{min}$, a time interval that was long enough for the rate of Etd $^{+}$fluorescence increase to reach a steady state. Then, the cells were mounted on the stage of a fluorescence microscope for time lapse imaging (Olympus BMX51). Images were captured by a digital camera (OrcaER, Hamamatsu) controlled by imaging software (Imaging Suite, version 5.5 , PerkinElmer) every $1 \mathrm{~min}$ (exposure time $=0.7 \mathrm{~s}$; excitation and emission wavelengths were $528 \mathrm{~nm} 598 \mathrm{~nm}$, respectively). The fluorescence intensity was defined as $\mathrm{F}-\mathrm{F}_{\text {background. The mean slope of the }}$ relationship $\left(\mathrm{F}-\mathrm{F}_{\text {background }}\right)$ over a given time interval $\left(\Delta \mathrm{F} / \Delta \mathrm{T} ; \mathrm{F}_{\text {back }^{-}}\right.$ ground remained constant over the time of recording) represents the rate of Etd $^{+}$uptake in control and in FGF-1-treated astrocytes. The rates of BzATP and FGF-1-induced uptake in single cells were correlated with the basal rates in those same cells (see Fig. $4 I, J$ ), and the rates of induced $\mathrm{Etd}^{+}$uptake were normalized to the basal rates. For treatments $<1 \mathrm{~h}$, not all cells in a given preparation responded; and when evaluating the population response, we considered a cell to respond if the rate of uptake rate increased by $>30 \%$ of the basal rate for that cell. For FGF treatments $>1$ $\mathrm{h}$, the fluorescence intensity was averaged for the same $8-10$ cells in each image and plotted in arbitrary units versus time. Microscope and camera settings remained the same in any series of measurements in which comparisons were made. To illustrate the rates of $\mathrm{Etd}^{+}$uptake in control versus FGF-1-treated cells, plots of fluorescence intensity versus time in single cells were set at the same fluorescence, $1 \mathrm{AU}$, at $\mathrm{T}=0 \mathrm{~s}$. All preparations were exposed to $\mathrm{Etd}^{+}$for the same length of time before uptake measurement. Over the time course of our experiments $(<40$ min), we observed no saturation of Etd ${ }^{+}$uptake. We found no difference in fluorescence intensity over time when images were acquired at $6 \mathrm{~s}$ rather than $1 \mathrm{~min}$ intervals, indicating that there was no significant bleaching.

Small interfering RNA against Px1 (siRNA Px1). Astrocyte cultures were treated with $0.2 \mu \mathrm{M}$ of siRNA Px1 targeting rat Px1 mRNA. We used 2 sequences of Stealth siRNA duplex oligoribonucleotides from Invitrogen: AUG AGC UUG CAC UGG AAG CUA UCG G and/or GAG CUC AAA UCG UAC AAG UGU CUU A. For control, we used the Invitrogen nontargeting siRNA, siRNA(-). For transfection, confluent cultures (90\%) were treated overnight with siRNA Px1 mixed with $10 \mu \mathrm{l} / \mathrm{ml}$ Lipofectamine reagent (Invitrogen). Transfection reagents were removed and cells incubated for 4-6 h in DMEM medium (2\% FBS) before treatment with FGF-1.

Calcium imaging. For calcium imaging, astrocytes were seeded in MatTek dishes $2-3 \mathrm{~d}$ before use. Cells were loaded for $30-40 \mathrm{~min}$ at $37^{\circ} \mathrm{C}$ with $5 \mu \mathrm{M}$ fura- $2 \mathrm{AM}$ in Tyrode's solution, washed, and incubated at room temperature for $5 \mathrm{~min}$ before the recordings. The dishes were mounted on the stage of a microscope (Olympus-IX70) equipped with the UltraView imaging system. Fluorescence images were acquired every 10 or $20 \mathrm{~s}$, and $\left[\mathrm{Ca}^{2+}\right]_{\mathrm{i}}$ was evaluated as the ratio of light $(520 \mathrm{~nm})$ emitted at two excitation wavelengths ( 340 and $380 \mathrm{~nm}$ ). In each experiment, $\sim 10-15$ cells were imaged and background subtracted. Oscillations have been described in astrocytes in culture as well as in slices (Tashiro et al., 2002; Morita et al., 2003), but with faster onset and offset than our $0.05-0.1 \mathrm{~Hz}$ sampling frequency. We performed a few experiments acquiring images at $0.5-1 \mathrm{~Hz}$. Oscillations with a period of $\sim 100 \mathrm{~s}$ and rise and fall time of 10-20 s appeared in cultured spinal astrocytes at a very low incidence $(<10 \%)$ and were not affected by FGF-1 (data not shown). $\left[\mathrm{Ca}^{2+}\right]_{\mathrm{i}}$ was measured before and after FGF-1 or ATP treatments. Calcium elevations after treatment with FGF-1 and ATP were measured both at the initial peak, defined as the maximum 340/380 fura- 2 fluorescence ratio after the treatment, and usually reached with 3 min of FGF-1 treatment and less after ATP treatment, and at the plateau or steady-state phase, in which $\left[\mathrm{Ca}^{2+}\right]_{\mathrm{i}}$ has a nearly constant value that persists while ATP or FGF-1 is in the bath. The plateau phase was measured after 10 or 15 min treatment, which is more than twice the $\tau$ of the exponential decay from the peak value. Fura- 2 is useful between $\sim 10 \mathrm{~nm}$ and $\sim 1 \mu \mathrm{M}$, but we did not calibrate the $340 / 380$ fluorescence ratios (Scemes et al., 2000). We recorded baseline ratio values from 0.05 to 0.2 with mean of $0.15 \pm 0.03$. In quantification of the calcium responses to FGF-1 and ATP, we normalized the value of each response to its own pretreatment baseline (see Figs. 1, 2).

Acute spinal cord and brain slices. One- to two-month-old mice in which one copy of chemokine receptor $\mathrm{CX}_{3} \mathrm{CR} 1$ gene was replaced by a gene encoding EGFP (https://www.jax.org/strain/008451) (Jung et al., 2000) were used to prepare acute spinal cord and cortical slices. In these mice, EGFP is expressed in microglia but not in other glial cells or in neurons (Jung et al., 2000). Other mice used to examine the role of microglia are explained below.

To prepare acute slices, mice were anesthetized using intraperitoneal injection of ketamine $(100 \mathrm{mg} / \mathrm{kg}) /$ xylazine $(15 \mathrm{mg} / \mathrm{kg})$ and perfused through the left ventricle with iced-cold ACSF saturated with $95 \%$ $\mathrm{O}_{2} / 5 \% \mathrm{CO}_{2}$. After perfusion, animals were decapitated and cerebral cortex or spinal cord was rapidly dissected. Spinal cords were embedded in $4 \%$ low melting point agarose before sectioning. Cortical coronal sections and spinal cross sections were made in ice-cold ACSF $\left(95 \% \mathrm{O}_{2} / 5 \%\right.$ $\mathrm{CO}_{2}$ ) with a Leica vibratome (VT $1000 \mathrm{~S}$ ). Slices were allowed to recover for $1 \mathrm{~h}$ at $35^{\circ} \mathrm{C}$ in saturated $95 \% \mathrm{O}_{2} / 5 \% \mathrm{CO}_{2}$ ACSF. Slices were stirred with $4 \mathrm{ml}$ of an ASCF solution containing $10 \mathrm{ng} / \mathrm{ml} \mathrm{FGF-1} \mathrm{and} \mathrm{heparin}$ (50 IU/ml) or heparin alone, and every 15 min washed with fresh ACSF solution of the same composition for $1 \mathrm{~h}$. In different experiments, U73122 (4 $\mu \mathrm{M})$, BAPTA-AM $(1 \mu \mathrm{M}),{ }^{10} \mathrm{Panx} 1$ or scrambled peptide $(100$ $\mu \mathrm{M}$, Tocris Bioscience, batch 5B or 5A, respectively), Gap19 (100 $\mu \mathrm{M}$, Tocris Bioscience, batch 1A), BBG (0.1-100 $\mu \mathrm{M})$, A740003 (0.1-100 $\mu \mathrm{M})$, and RB2 $(0.1-100 \mu \mathrm{M})$ were added to the ACSF solution containing FGF-1 and heparin or heparin alone. Blockers were applied in ASCF 10 min before FGF-1 and heparin or heparin alone were added. After application for $1 \mathrm{~h}$ of FGF-1 and heparin or heparin alone without or with blockers, $\mathrm{Etd}^{+}$uptake was measured over $10 \mathrm{~min}$ by adding $5 \mu \mathrm{M}$ EtdBr in saturated $95 \% \mathrm{O}_{2} / 5 \% \mathrm{CO}_{2}$. To remove unbound $\mathrm{Etd}^{+}$, slices were rinsed 3 times with PBS before fixing them for $2 \mathrm{~h}$ at room temperature or overnight at $4^{\circ} \mathrm{C}$ with $4 \%$ PFA in PBS. Etd ${ }^{+}$labeling was stable to fixation and permeabilization for $\sim 1$ week, and comparisons were made between slices treated in the same ways with and without FGF-1 1-2 d after labeling with EtdBr.

For immunostaining of GFAP, Etd ${ }^{+}$-labeled slices were first permeabilized in Triton X-100 ( $1 \%$ in PBS) for $3 \mathrm{~h}$ and blocked with a solution containing 5\% donkey serum, $0.5 \%$ BSA, and $0.1 \%$ Triton X-100 in PBS for $0.5 \mathrm{~h}$. Slices were incubated for $1 \mathrm{~h}$ with chicken anti-GFAP (Millipore, lot \#2571241) and then incubated $1 \mathrm{~h}$ with goat anti-chicken conjugated Alexa-647 (Abcam). To confirm that $\mathrm{CX}_{3} \mathrm{CR} 1$ cells express a microglia marker, slices prepared from $\mathrm{CX}_{3} \mathrm{CR} 1^{\mathrm{EGFP}}$ mice were stained with rabbit anti-Ibal (Wako) and anti-rabbit conjugated Alexa-647 (eBioscience). Slices were mounted in Mowiol 4-88. Images were taken with a Zeiss 710 confocal microscope equipped with $20 \times$ or $40 \times$ (oilimmersion) objectives and appropriate filters.

$F$ was measured at the soma for single cells expressing $\mathrm{CX}_{3} \mathrm{CR} 1$ or GFAP. Cells were identified in the 3D images generated through $z$-axis projection $\left(z\right.$-stack). For individual slices, Etd ${ }^{+}$fluorescence was calibrated in an 8-bit scale, ranging from $\mathrm{F}_{\text {background }}=0$ to $\mathrm{F}_{\max }=255 \mathrm{AU}$. $\mathrm{F}_{\text {background }}$ was measured in blood vessel areas; $\mathrm{F}_{\max }$ was taken at the brightest region in the projection. We constructed distribution histograms of the $\mathrm{Etd}^{+}$uptake in astrocytes $(75 \pm 30 \mathrm{AU}$, mean $\pm \mathrm{SD}, n=300$ cells) and quantified the fraction of astrocytes with $\mathrm{Etd}^{+}$fluorescence $>105 \mathrm{AU}($ mean $\pm \mathrm{SD})$. We refer to this population of cells as high Etd ${ }^{+}$ astrocytes. The frequency of astrocytes showing low to medium uptake $(<105 \mathrm{AU})$ and high $\mathrm{Etd}^{+}$uptake $(>105 \mathrm{AU})$ in FGF-1-treated and control slices was significantly different $\left(p<0.0001, \chi^{2}\right.$ test, $\left.1 \mathrm{dF}\right)$. To quantify the maximal capacity of $\mathrm{Etd}^{+}$accumulation by the cell, we incubated slices overnight with EtdBr after tissue was fixed in 4\% PFA and permeabilized (1\% Triton X-100). Mean $\mathrm{Etd}^{+}$fluorescence measured from different types of cell in the slices was $170 \pm 30 \mathrm{AU}$ (mean \pm $\mathrm{SD}, n=300$ cells, 3 slices).

To quantify the morphological signs of microglial activation after FGF-1 treatment, the total area of $\mathrm{CX}_{3} \mathrm{CR} 1{ }^{+}$cells in the $z$-projection was 


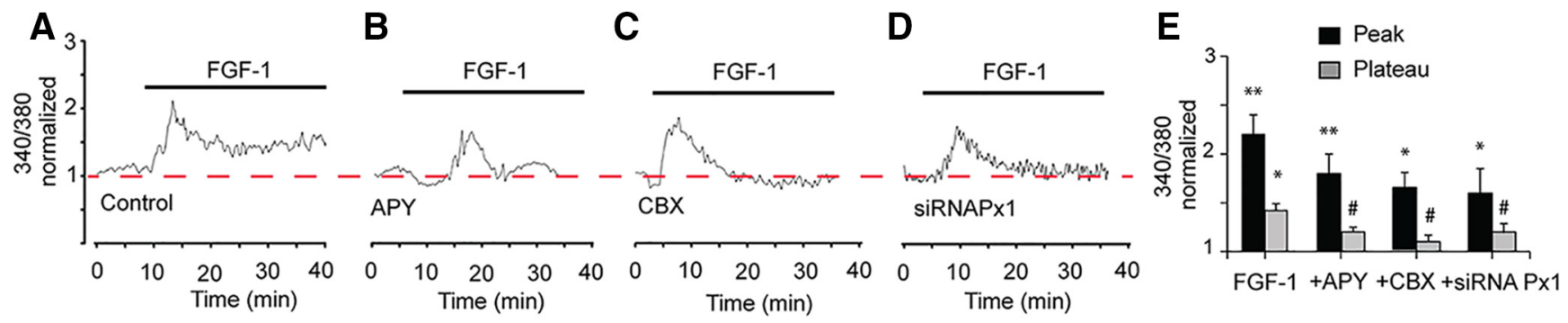

Figure 1. FGF-1 increases basal $\left[\mathrm{Ca}^{2+}\right]_{\mathrm{i}}$ in spinal astrocytes. Bars above the recordings represent application of $10 \mathrm{ng} / \mathrm{ml} \mathrm{FGF-1.}\left[\mathrm{Ca}^{2+}\right]_{\mathrm{i}}$ was measured as the ratio of $340 / 380 \mathrm{~nm}$ fura- 2 emission normalized to basal. $\boldsymbol{A}$, FGF-1 induced a fast (minutes) rise in $\left[\mathrm{Ca}^{2+}\right]_{\mathrm{i}}$, which decayed to a plateau. $\boldsymbol{B}$, Ten minute pretreatment with $2 \mathrm{mU} / \mathrm{ml}$ APY and continued application of APY with FGF-1 abolished the plateau phase but only moderately reduced the peak. C, The same result was obtained with $200 \mu \mathrm{m}$ CBX using the same protocol. D, Transfection of astrocytes for $24 \mathrm{~h}$ with siRNA PX1 also abolished the plateau phase and reduced the peak. $\boldsymbol{E}$, Quantitation of $\left[\mathrm{Ca}^{2+}\right]_{\mathrm{i}}$ responses to FGF- 1 application as in $\boldsymbol{A}-\boldsymbol{D} . n=4 .{ }^{*} p<0.05$ versus basal. ${ }^{* *} p<0.01$ versus basal. ${ }^{\sharp} p<0.05$ plateaus FGF-1 + blocker versus FGF-1 alone.

calculated in a binary image (in a $300 \mu \mathrm{m}$ slice, with $z=0$ starting $30 \mu \mathrm{m}$ below the slice surface and extending $70 \mu \mathrm{m}$ deeper) using ImageJ software. The binary image was set at a threshold of $1.2 \times \mathrm{F}_{\text {background }}$, which was determined in a region without cells (e.g., inside of a blood vessel). The area occupied by the microglia images was expressed as a percentage of the total area examined.

Microglia depletion experiments. $\mathrm{CX}_{3} \mathrm{CR} 1^{\mathrm{CreER} / \mathrm{CreER}}$ mice were kindly provided to us by Dr. Wenbiao Gan (New York University) and crossed with mice harboring the Rosa26 ${ }^{\text {iDTR/iDTR }}$ alleles (R26 ${ }^{\text {iDTR/iDTR }}$; https:// www.jax.org/strain/007900; The Jackson Laboratory) (Buch et al., 2005). In Rosa26 ${ }^{\mathrm{DDTR} / \mathrm{iDTR}}$ mice, the open reading frame for the diphtheria toxin receptor (DTR) and an upstream lox-P flanked stop cassette sequence are inserted in the Rosa26 locus, which is ubiquitously expressed in mouse tissues. Heterozygous F1 mice with genotype $\mathrm{CX}_{3} \mathrm{CR} 1{ }^{\mathrm{CreER} /+}$, $\mathrm{R} 26^{\mathrm{iDTR} /+}$ were used for experiments. To activate Cre-mediated recombination of DTR specifically in microglia, $\mathrm{CX}_{3} \mathrm{CR} 1^{\mathrm{CreER} /+}$ : $\mathrm{R} 26{ }^{\mathrm{iDTR} /+}$ adult mice were given $0.35 \mathrm{mg}$ of tamoxifen/g/d for $3 \mathrm{~d}$. To induce microglia depletion, DTRs were activated by intraperitoneal administration of $1 \mu \mathrm{g}$ of diphtheria toxin (DT)/d for $3 \mathrm{~d}, 20-30 \mathrm{~d}$ after tamoxifen treatment (Parkhurst et al., 2013). $\mathrm{CX}_{3} \mathrm{CR} 1^{\mathrm{CreER} /+}$ mice without the $\mathrm{R} 26^{\mathrm{iDTR} /+}$ allele were also treated with tamoxifen and DT as explained above and used as controls. Depletion of microglia was confirmed by immunostaining for Iba1.

ELISA. Mice were deeply anesthetized and perfused with $25 \mathrm{ml}$ of $\mathrm{Ca}^{2+} / \mathrm{Mg}^{2+}$-free ice-cold ACSF to remove remaining blood. Spinal cord slices were prepared and maintained in ASCF as described above for a period not longer than $2 \mathrm{~h}$. Ten to 15 slices per experimental condition ( $\sim 0.5-1 \mathrm{mg}$ of tissue protein) were harvested and disrupted by sonication in NP-40 lysis buffer (50 mm Tris, pH 7.4, $150 \mathrm{~mm} \mathrm{NaCl}, 1 \%$ NP-40, $0.1 \%$ Triton $\mathrm{X}-100$, and $0.1 \%$ SDS). The homogenized material was centrifuged at $20,000 \times g$ for $15 \mathrm{~min}$, and the cleared supernatant was collected for analysis. Total protein levels in CNS homogenates were determined by BCA assay (Pierce). IL- $1 \beta$, IL- 6 , and TNF $\alpha$ protein levels were measured using the Mouse Platinum ELISA kit (eBioscience). Samples were processed according to the manufacturer's instructions.

Statistics. Data are presented as mean $\pm \mathrm{SE} ; n$ values are the number of independent experiments, culture dishes, or slices from at least 3 animals, or number of animals used. Depending on the procedure, means for $10-15$ cells were determined for each experiment in cultures, and 50100 cells for each experiment in slices. Means for each group were compared using the nonparametric Mann-Whitney $U$ test. A $\chi^{2}$ test was also used for data shown in Figure 6 as indicated. Differences were considered significant at $p<0.05$. Statistics were calculated using Graph Pad Prism 6 (2014) software. Figures were prepared using excel, Sigma Plot 2010, and Adobe Illustrator CC.

\section{Results}

FGF-1 increases intracellular calcium concentration in cultured spinal astrocytes

Application of FGF-1 with heparin increased $\left[\mathrm{Ca}^{2+}\right]_{\mathrm{i}}$ in spinal astrocytes in culture (single representative cells in Fig. $1 A-D$,
10-15 cells in each of 4 cultures for each experiment in Fig. 1E). The initial increase in $\left[\mathrm{Ca}^{2+}\right]_{\mathrm{i}}$, measured as the ratio of $340 \mathrm{~nm} /$ $380 \mathrm{~nm}$ emission ( $\mathrm{R}$, normalized to the basal level), reached a maximum value at $2.13 \pm 0.15$ times basal in $<5 \mathrm{~min}(p<0.001$, $n=4$; Fig. $1 A, E)$. Over the next $\sim 5 \mathrm{~min},\left[\mathrm{Ca}^{2+}\right]_{\mathrm{i}}$ decayed to a plateau phase of $1.40 \pm 0.05$ times basal $(p<0.05$ vs basal, $n=$ $4)$. The response to FGF-1 was not uniform across the cultured cells; $\left[\mathrm{Ca}^{2+}\right]_{\mathrm{i}}$ was elevated transiently in $80 \pm 17 \%$ of the cells and decayed to a plateau in $40.0 \pm 9.0 \%$ of responding cells; in the other responding cells, $\left[\mathrm{Ca}^{2+}\right]_{\mathrm{i}}$ decayed to the baseline. In Figure $1 E$, plotted plateau values were from the responding cells. The cultures in these experiments were at low density. Thus, at least the early rises in $\left[\mathrm{Ca}^{2+}\right]_{\mathrm{i}}$ were not a result of $\mathrm{Ca}^{2+}$ spread between cells via gap junctions. Also, FGF-1 reduces coupling between astrocytes (Garré et al., 2010). After 7 h FGF-1 treatment, recording for 5 min after washout of FGF-1 showed that $\left[\mathrm{Ca}^{2+}\right]_{\mathrm{i}}$ was still elevated (see Fig. $5 D$ ), suggesting that the early plateau $(<1 \mathrm{~h}$ FGF-1 treatment) can persist for relatively long times in cultures of spinal astrocytes.

In the presence of APY $(2 \mathrm{mU} / \mathrm{ml})$, the peak of FGF-1-induced increase in $\left[\mathrm{Ca}^{2+}\right]_{\mathrm{i}}$ was $1.85 \pm 0.11$ times basal $(p>0.05$ vs FGF-1 alone, $n=4)$, and the plateau level $\left[\mathrm{Ca}^{2+}\right]_{\mathrm{i}}$ was not significantly different from basal $(p>0.05, n=4)$ but was different from the plateau phase induced by FGF-1 alone $(p<0.05$ vs FGF-1). These data suggest that FGF-1-induced secretion of ATP contributes to the plateau phase by an autocrine/paracrine action of ATP (Fig. $1 B, E$ ). Pretreatment of astrocytes with $200 \mu \mathrm{M}$ carbenoxolone (CBX) or knockdown of Px1 expression with siRNA (siRNA Px1; Fig. 1C-E) did not significantly affect the initial $\mathrm{Ca}^{2+}$ transient; however, these treatments abolished (CBX) or reduced (siRNA Px1) the plateau ( $\mathrm{R}$ normalized to basal; after treatment with FGF-1 in the presence of CBX, peak: $1.66 \pm 0.10$ times basal, $p>0.05$ vs FGF- 1 alone; plateau: $1.01 \pm 0.07$ times basal, $p>0.05$ vs basal; for siRNA Px1, peak: $1.61 \pm 0.10$ times basal, $p<0.05$ vs FGF-1 alone; plateau: $1.15 \pm 0.03$ times basal, $p>0.05$ vs basal, $n=4)$. These data indicate that astrocytes respond to FGF-1 by increasing $\left[\mathrm{Ca}^{2+}\right]_{\mathrm{i}}$ and releasing ATP. We show below that ATP activates purinergic receptors that then open Px1 HCs and mediate the plateau phase of $\left[\mathrm{Ca}^{2+}\right]_{\mathrm{i}}$ increase in response to FGF-1.

To further characterize how ATP release affects calcium signaling in response to FGF-1, we treated spinal astrocytes with exogenous ATP. The rise of the $\left[\mathrm{Ca}^{2+}\right]_{\mathrm{i}}$ increase in response to drug application was faster for ATP (1 mM) than for FGF-1, but the peak values of $\mathrm{R}$ (normalized to basal) were similar for the durations tested, $1-10 \min \left(R_{1 \min }=1.52 \pm 0.02, p<0.05\right.$ vs 
A

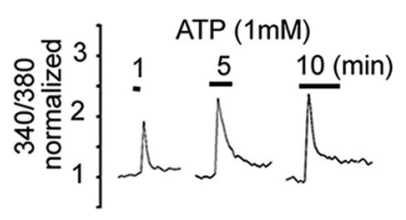

01020
Time (min)

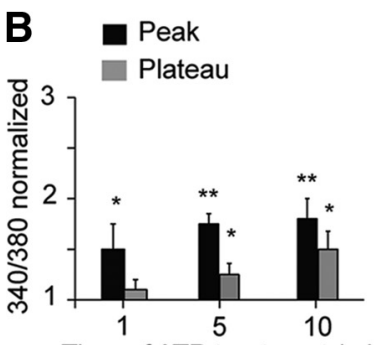

Time of ATP treatment $(\mathrm{min})$
C

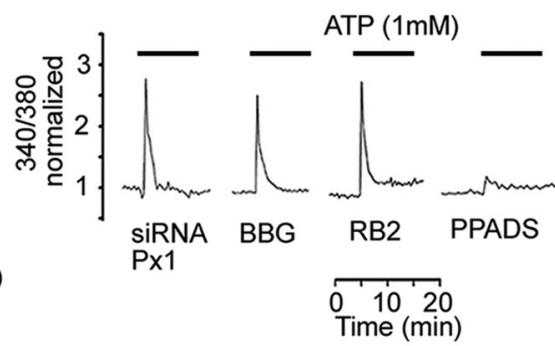

D $\quad$ Peak

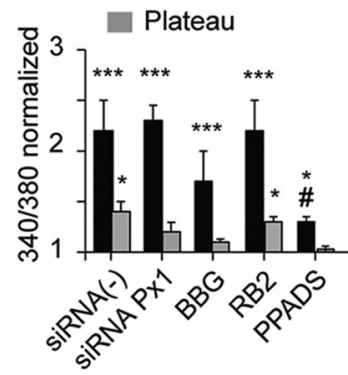

Figure 2. ATP promotes calcium influx through P2XRs and Px1 HCs. $\left[\mathrm{Ca}^{2+}\right]_{\mathrm{i}}$ measured as in Fig. 1. $\boldsymbol{A},\left[\mathrm{Ca}^{2+}\right]_{\mathrm{i}}$ responses of spinal astrocytes exposed to $1 \mathrm{~mm}$ ATP for 1,5 , or $10 \mathrm{~min}$ showed increasing peak and plateau amplitude. $B$, Summary of $\left[\mathrm{Ca}^{2+}\right]_{\mathrm{i}}$ responses to $1 \mathrm{~mm} \mathrm{ATP} \mathrm{applied} \mathrm{for} \mathrm{different} \mathrm{periods} \mathrm{measured} \mathrm{at} \mathrm{the} \mathrm{peak} \mathrm{(black} \mathrm{bars)} \mathrm{and} \mathrm{during} \mathrm{the} \mathrm{plateau} \mathrm{(} \sim 5$ min after the peak; gray bars). $C,\left[\mathrm{Ca}^{2+}\right]_{\mathrm{i}}$ measured in cells treated for 10 min with $1 \mathrm{~mm}$ ATP after $24 \mathrm{~h}$ treatment with siRNA Px 1 or in the presence of $10 \mu \mathrm{m} \mathrm{BBG,} 50 \mu \mathrm{m}$ RB2, and $50 \mu \mathrm{m}$ PPADS. Bars above the traces represent the application of ATP. The peak response was unaffected by siRNA PX1, BBG, or RB2, but the subsequent plateau was blocked by siRNA PX1 and by BBG and reduced by RB2. PPADS largely blocked both the initial peak and the plateau. $\boldsymbol{D}$, Summary of $\left[\mathrm{Ca}^{2+}\right]_{\mathrm{i}}$ responses to $10 \mathrm{~min}$ application of $1 \mathrm{~mm}$ ATP and blockers. $n=4-6 .{ }^{*} p<0.05$ versus basal before ATP treatment. ${ }^{* *} p<0.01$ versus basal before ATP treatment. ${ }^{* *} p<0.001$ versus basal before ATP treatment. ${ }^{\#} p<0.05$ versus ATP alone.

basal, $\mathrm{R}_{5 \text { min }}=1.75 \pm 0.1, \mathrm{R}_{10 \text { min }}=1.82 \pm 0.13, p<0.001 \mathrm{vs}$ basal, $n=6$; Fig. $2 A, B)$. In contrast to the relative constancy of the peak, the plateau phase of $\mathrm{R}$ progressively increased in amplitude with longer ATP application $\left(\mathrm{R}_{1 \text { min }}=1.09 \pm 0.02, p>0.05\right.$ vs basal; $\mathrm{R}_{5 \text { min }}=1.25 \pm 0.12, p<0.05$ vs basal; $\mathrm{R}_{10 \text { min }}=1.46 \pm$ $0.11, p<0.05$ vs basal, $n=6$; Fig. $2 A, B)$.

The peak values of $\left[\mathrm{Ca}^{2+}\right]_{\mathrm{i}}$ after ATP application for $10 \mathrm{~min}$ were not significantly different between control astrocytes and astrocytes transfected with siRNA Pxl or nontargeting siRNA (ATP alone: $1.8 \pm 0.2, p<0.01$ vs basal; Fig. $2 B$; $\operatorname{siRNA}(-): 2.2 \pm 0.3 ; p>0.05 \mathrm{vs}$ ATP alone, $p<0.001$ vs basal; siRNA Px1: $2.3 \pm 0.2 ; p>0.05$ vs ATP alone, $p<0.001$ vs basal; $n=4$; Fig. $2 C, D$ ). Moreover, peak responses to ATP were not significantly changed by pretreatment with $10 \mu \mathrm{M}$ BBG, a P2X $\mathrm{X}_{7} \mathrm{R}$ antagonist $(1.7 \pm 0.4, p>0.05$ vs ATP alone, $n=5)$, or $50 \mu \mathrm{M} \mathrm{RB} 2$, a nonselective $\mathrm{P} 2 \mathrm{Y}$ antagonist $(2.2 \pm 0.3, p>$ 0.05 vs ATP alone, $n=5$ ). However, $50 \mu \mathrm{M}$ of the nonselective P2X blocker PPADS largely blocked the peak responses $(1.2 \pm 0.001, p<$ 0.05 vs ATP alone, $n=4$; Fig. $2 C, D)$.

The $\left[\mathrm{Ca}^{2+}\right]_{\mathrm{i}}$ elevation at the plateau measured $\sim 5$ min after start of ATP application was prevented by siRNA Px1 $(1.1 \pm 0.05$, $p>0.05$ vs basal, $n=5)$ and BBG ( $1.01 \pm 0.05, p>0.05$ vs basal, $n=4)$ and decreased by a high concentration of RB2, but to levels that were still significantly above basal $(1.25 \pm 0.02, p<0.05$ vs basal, $n=4$; Fig. $2 C, D$ ). Application of $50 \mu \mathrm{M}$ PPADS abolished the $\left[\mathrm{Ca}^{2+}\right]_{\mathrm{i}}$ plateaus (PPADS: $1.01 \pm 0.03, p<0.05$ vs ATP alone, $n=4$; Fig. $2 C, D)$. Together, these data suggest that the first phase in $\left[\mathrm{Ca}^{2+}\right]_{\mathrm{i}}$ rise in response to ATP is mediated by purinergic receptors, probably different from $\mathrm{P}_{2} \mathrm{X}_{7} \mathrm{Rs}$, and not by $\mathrm{Px} 1 \mathrm{HCs}$. By the time the plateau phase begins $(\sim 5$ min after ATP application), most of the P2XRs initially activated by ATP (P2X $\mathrm{X}_{1}, \mathrm{P}_{2} \mathrm{X}_{2}$, $\mathrm{P} 2 \mathrm{X}_{3}, \mathrm{P} 2 \mathrm{X}_{5}$ ) should be desensitized (North, 2002; Khakh and North, 2012), which makes unlikely their participation during this phase, and the effects of BBG and siRNA Px1 (and the minor effect of a high RB2 concentration) suggest mediation by opening of $\mathrm{P} 2 \mathrm{X}_{7} \mathrm{Rs}$ and Px1 HCs.

FGF-1 increases Etd ${ }^{+}$permeability through activation of PLC and calcium release from endoplasmic reticulum

To determine whether $\mathrm{HC}$ opening underlies the increase in membrane permeability to large dyes in cultured spinal astrocytes, we measured the rates of Etd ${ }^{+}$uptake by these cells as previously described (Contreras et al., 2002, 2003; Bennett et al., 2003). Liganded FGF receptors activate PLC and increase $\left[\mathrm{Ca}^{2+}\right]_{\mathrm{i}}$ through IP3 action on its receptors in the ER membrane (Reuss and von Bohlen und
Halbach, 2003), and FGF-1 causes increase in Etd ${ }^{+}$uptake by astrocytes in culture (Garré et al., 2010), which is mediated by Px1 HCs and $\mathrm{Cx} 43 \mathrm{HCs}$. To link FGF-1-dependent calcium responses to HCmediated $\mathrm{Etd}^{+}$uptake, we used BAPTA-AM to buffer $\left[\mathrm{Ca}^{2+}\right]_{\mathrm{i}}$, U73122 to inhibit PLC and, as a control, U73343, a chemical analog of U73122 that does not inhibit PLC (Hong et al., 2006). These reagents were applied 15 min before and during FGF-1 application. Application of FGF-1 alone enhanced Etd ${ }^{+}$uptake rates with a latency of $\sim 5 \mathrm{~min}$ in $42.5 \pm 2.5 \%$ of treated cells (single cell recording in Fig. $3 A$, quantification in Fig. $3 F$ ). The percentage of cells increasing $\mathrm{Etd}^{+}$uptake was smaller than that of cells showing $\mathrm{Ca}^{2+}$ responses but comparable with that of cells showing $\left[\mathrm{Ca}^{2+}\right]_{\mathrm{i}}$ plateaus $(40.0 \pm 5.2 \%)$. In astrocytes pretreated with $1 \mu \mathrm{M}$ BAPTA-AM, no cells increased uptake in response to FGF-1 (rate of Etd ${ }^{+}$uptake was $1.05 \pm 0.01$ times basal, $p>0.05$ vs control, $n=4$; Fig. $3 B, F)$. Neither U73122 nor U73343 affected basal $\left[\mathrm{Ca}^{2+}\right]_{\mathrm{i}}$ level $(0.9 \pm 0.2$, $p>0.05$ vs basal, $n=4)$ or basal Etd ${ }^{+}$uptake $(1.0 \pm 0.1, p>0.05 \mathrm{vs}$ basal, $n=4)$. U73122 (4 $\mu \mathrm{M})$ reduced the percentage of cells showing an increase in uptake to $13.3 \pm 3.0 \%(p<0.001$ vs $\mathrm{U} 73343+$ FGF-1, $n=4$; Fig. $3 F$ ) and reduced the rate of FGF-1-induced Etd ${ }^{+}$ uptake in responding cells (to $1.8 \pm 0.2$ times basal; $p<0.05$ vs $\mathrm{U} 73343+$ FGF-1 or $p<0.01$ vs basal, $n=4$; Fig. $3 D, G)$. U73122 also reduced the percentage of cells responding to FGF-1 with an increase in $\left[\mathrm{Ca}^{2+}\right]_{\mathrm{i}}$ (to $5.0 \pm 2.8 \%, n=4, p<0.001$ vs $70 \pm 10 \%$ in U73343; Fig. 3E). U73343 (4 $\mu \mathrm{M})$ did not affect FGF-1-mediated increase in $\mathrm{Etd}^{+}$uptake, which presumably occurred in cells that had a plateau of elevated $\left[\mathrm{Ca}^{2+}\right]_{\mathrm{i}}$ (U73343 + FGF-1 vs FGF-1 alone, $p>0.05$; U73343 + FGF-1 vs basal, $p<0.001, n=4$; Fig. $3 A, C, F)$. U73343 also did not reduce the percentage of cells showing increase in $\left[\mathrm{Ca}^{2+}\right]_{\mathrm{i}}$ in response to FGF-1 $(70 \pm 12 \%, p>0.05$ vs FGF- 1 alone, $n=4$; Fig. $3 E$ ).

After 7 h FGF-1 treatment $>80.0 \pm 11.0 \%$ of the cultured astrocytes showed increase in $\mathrm{Etd}^{+}$uptake (to $3.8 \pm 0.5$ times basal, $n=6$ ). In these experiments, the rate of $\mathrm{Etd}^{+}$uptake was averaged across all cells. The rate of Etd ${ }^{+}$uptake was reduced by $\mathrm{U} 73122$ (to $2.2 \pm 0.2$ times basal, $p<0.05$ vs $\mathrm{U} 73343$ or $p<0.01$ vs basal, $n=4$ ), but not by U73343 (to $3.0 \pm 0.5$ times basal, $p<$ 0.001 vs basal, $p>0.05$ vs FGF- 1 alone, $n=4$; Fig. $3 H$ ). This result indicates that, after $7 \mathrm{~h}$ FGF- 1 treatment, there is still PLC activity contributing to the FGF-1 response and that the selfsustaining ATP release through $\mathrm{P}_{2} \mathrm{X}_{7} \mathrm{R}$ activation and opening of Px1 HCs (and also Cx43 HCs) is not responsible for the entire permeabilization response. 
A
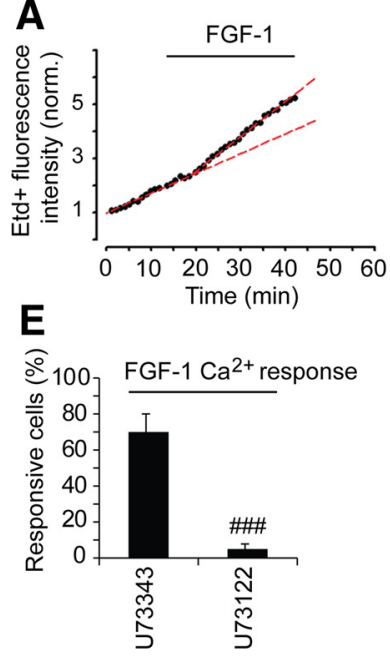

B

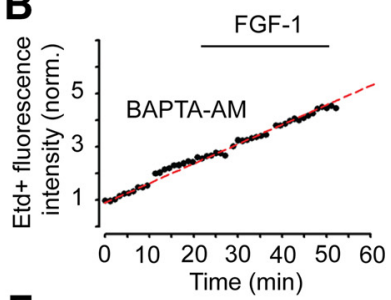

F

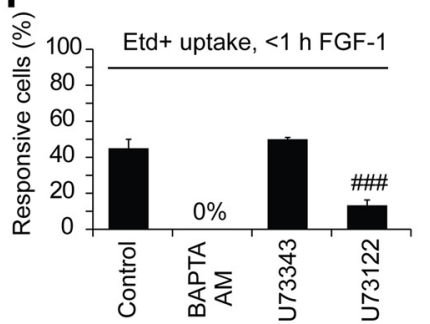

C

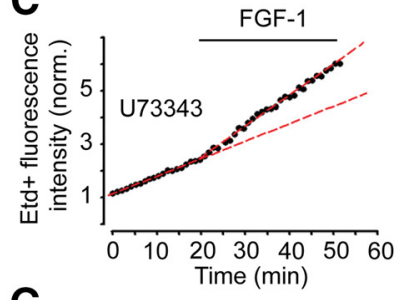

G

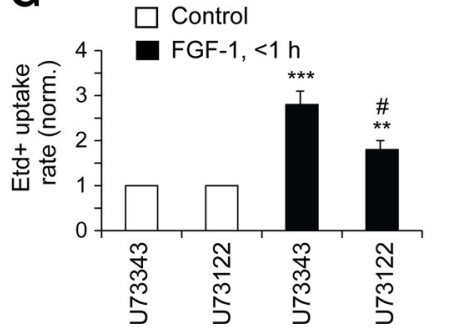

D

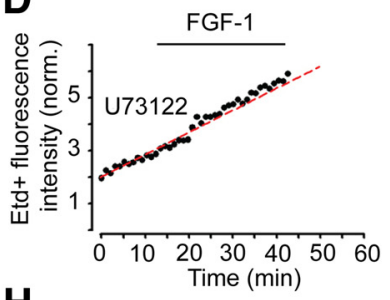

H

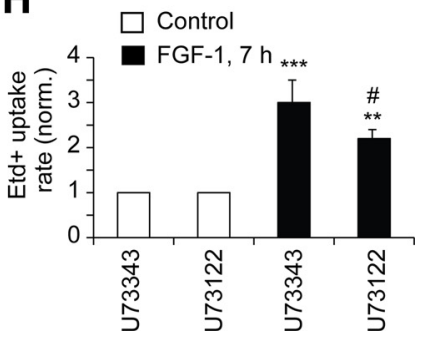

Figure 3. Increase in Etd ${ }^{+}$permeability induced by FGF-1 depends on activation of PLC and calcium release from intracellular stores. Single-cell recordings from responsive cells in $\boldsymbol{A}-\boldsymbol{D}$. FGF-1 treatment increased rate of Etd ${ }^{+}$uptake by spinal astrocytes $(\boldsymbol{A})$; this increase was prevented by 10 min pretreatment with BAPTA-AM $(\boldsymbol{B})$, not affected in the presence of the inactive analog U73343 $(4 \mu \mathrm{m})$ of the PLC blocker U73122 (C), and greatly reduced by U73122 (4 $\mu \mathrm{M})(\boldsymbol{D})$. Red dashed lines indicate the measured uptake rates. $\boldsymbol{E}$, Quantitation of percentage of cells showing increase in $\left[\mathrm{Ca}^{2+}\right]_{\mathrm{i}}(>30 \%$ times basal) shortly after FGF-1 application following pretreatment with U73343 or U73122. F, Quantitation of the effect of BAPTA-AM, U73343, and U73122 on percentage of cells showing increased uptake of Etd ${ }^{+}$in response to short-lasting ( $\left.<1 \mathrm{~h}\right)$ FGF-1 treatment. Control is FGF-1 alone. $\mathbf{G}$, Etd ${ }^{+}$uptake induced by short-lasting ( $<1 \mathrm{~h}$ ) FGF-1 treatment in the presence of U73343 or U73122 (normalized to basal uptake in the presence of U73343 or U731222 alone, which had no significant effect on basal uptake). $\boldsymbol{H}$, As in $\mathbf{G}$, but with $7 \mathrm{~h}$ FGF-1. $\mathbf{C}-\mathbf{G}$, U73343 and U73122 were applied $5 \mathrm{~min}$ before the start of recording (i.e., $20-25$ min before FGF- 1 application). $\boldsymbol{H}$, U73343 and U73122 were applied $1 \mathrm{~h}$ before completion of $7 \mathrm{~h}$ treatment with FGF-1. $n=$ 4. ${ }^{* *} p<0.01$ versus control. ${ }^{* * *} p<0.001$ versus control. ${ }^{\#} p<0.05$ versus U73343 + FGF-1 treatment. ${ }^{\# \# \# ~} p<0.001$ versus U73343 + FGF-1 treatment.

\section{P2X $\mathrm{X}_{7}$ Rs and Px1 HCs mediate the increase in membrane permeability induced by FGF-1 and ATP in cultured spinal astrocytes}

$\mathrm{P} 2 \mathrm{X}_{2} \mathrm{Rs}, \mathrm{P} 2 \mathrm{X}_{4} \mathrm{Rs}$, and $\mathrm{P} 2 \mathrm{X}_{7}$ Rs appear to become permeable to large molecules, such as organic cations and fluorescent tracers over seconds to minutes in response to ATP application (Khakh and North, 2012). However, this property is not observed in other P2XRs, such as $\mathrm{P}_{2} \mathrm{X}_{1} \mathrm{R}, \mathrm{P} 2 \mathrm{X}_{3} \mathrm{R}$, and $\mathrm{P} 2 \mathrm{X}_{5} \mathrm{R}$ (North, 2002). One mechanism proposed for the apparent shift in permeability is dilation of the channel pore, although an alternative explanation involves changes in ionic concentration gradients (Li et al., 2015). In many cell types, Px1 HCs act as accessory channels that increase membrane permeability after $\mathrm{P} 2 \mathrm{X}_{7} \mathrm{R}$ activation (Pelegrin and Surprenant, 2006). To confirm that $\mathrm{P} 2 \mathrm{X}_{7} \mathrm{R}$ activation triggers Px1 HC-mediated $\mathrm{Etd}^{+}$uptake in spinal astrocytes, we treated astrocyte cultures with the synthetic P2XR agonist, BzATP, which is more potent than ATP in opening Px1 HCs by activation of $\mathrm{P}_{2} \mathrm{X}_{7}$ Rs (Donnelly-Roberts et al., 2009). Rat spinal astrocytes treated with BzATP $(35 \mu \mathrm{M})$ rapidly $(<30 \mathrm{~s})$ increased Etd $^{+}$uptake rate (to $3.5 \pm 0.7$ times basal, $p<0.001$ vs basal, $n=$ 7; Fig. $4 A$ ). BzATP-induced increase in $\mathrm{Etd}^{+}$uptake was prevented in cells transfected with siRNA Pxl $(p<0.001$ vs BzATP, $n=4,10-15$ cells tested in each experiment; Fig. $4 B, F)$ and blocked in cells treated with the noncompetitive $\mathrm{P}_{2} \mathrm{X}_{7} \mathrm{R}$ antagonist BBG $(10 \mu \mathrm{M}, 1.1 \pm 0.4$ times basal, $p<0.001$ vs BzATP, $n=$ 5; Fig. $4 C, F)$. Because BBG has also been reported to affect macroscopic currents and dye uptake mediated by both $\mathrm{P}_{2} \mathrm{X}_{7} \mathrm{Rs}$ and Px1 HCs, we applied A740003, a more specific (competitive) antagonist of $\mathrm{P}_{2} \mathrm{X}_{7}$ Rs (Honore et al., 2006) (Fig. 4D,F). A740003 treatment $(75 \mu \mathrm{M})$ markedly reduced the BzATP-induced increase in $\mathrm{Etd}^{+}$uptake (to $1.2 \pm 0.4$ times basal, $p<0.001$ vs BzATP alone, $n=5$ ).

FGF-1 enhanced $\mathrm{Etd}^{+}$uptake rate (to $2.8 \pm 0.3$ times basal in responding cells, $n=10,10$ - 15 cells tested in each experiment determined after $<1$ h FGF-1 treatment; Figs. $3 A, 4 G$ ), and this increase was prevented by knocking down Pxl with siRNA Px1 (rate $1.3 \pm 0.3$ times basal, $p>0.05$ vs basal, $n=4$; FGF- $1+$ siRNA vs FGF-1 alone, $p<0.001$; Fig. $4 G$ ). The FGF-1-induced increase in $\mathrm{Etd}^{+}$uptake was blocked by $200 \mu \mathrm{M} \mathrm{CBX}$, which at this concentration inhibits both Px1 HCs and Cx43 HCs (rate $1.1 \pm 0.1$ times basal, $p>0.05$ vs basal, $n=4$; Fig. $4 G$ ). In contrast, $0.7 \mathrm{~mm}$ heptanol, a blocker of connexin-based GJs and HCs, did not affect Etd ${ }^{+}$uptake (rate $2.9 \pm 0.6$ times basal, $p<$ 0.01 vs basal, $p>0.05$ vs FGF- 1 alone, $n=4$; Fig. $4 G$ ). These data suggest that Px1 HCs mediate Etd ${ }^{+}$uptake. To further confirm that $\mathrm{P} 2 \mathrm{X}_{7} \mathrm{R}$ activation requires ATP and contributes to increase $\mathrm{Etd}^{+}$uptake in response to FGF-1 treatment, we pretreated astrocytes with APY $(2 \mathrm{mU} / \mathrm{ml})$ and with A740003 $(75 \mu \mathrm{M})$. APY and A740003 reduced the FGF- 1 induced uptake to $1.2 \pm 0.2$ and $1.2 \pm 0.3$ times basal, respectively $(p<0.001$ vs FGF- 1 alone, $n=$ 4; Fig. 4H).

The basal rate of $\mathrm{Etd}^{+}$uptake by control astrocytes was not affected by transfection with siRNA Px1 $(0.8 \pm 0.3$ times control $\operatorname{siRNA}(-), p>0.05$ vs control, $n=4$; Fig. $4 E$ ) or by $10 \mu \mathrm{M} \mathrm{BBG}$ ( $1.0 \pm 0.2$ times control, $p>0.05$ vs control, $n=4$ ), $75 \mu \mathrm{M}$ A740003 ( $1.1 \pm 0.3$, times control, $p>0.05$ vs control, $n=4)$, $200 \mu \mathrm{M}$ CBX ( $1.0 \pm 0.3$ times control, $p>0.05$ vs control $), 0.7$ mM heptanol ( $1.4 \pm 0.4$ times control, $p>0.05$ vs control, $n=4)$, or $2 \mathrm{mU} / \mathrm{ml}$ APY $(0.8 \pm 0.3$ times control, $p>0.05$ vs control, $n=4$; Fig. $4 E$ ). These data suggest that induced and basal uptake depend on different mechanisms.

In Figures 3 and 4, rates of BzATP-induced and FGF-1induced $\mathrm{Etd}^{+}$uptake were normalized to the rate of basal uptake in the same cells. The rates of uptake before and after BzATP or FGF-1 application were correlated $\left(R^{2}=0.8385\right.$, BzATP vs basal and $R^{2}=0.6277$, FGF- 1 vs basal; Fig. $\left.4 I, J\right)$. A possible reason for the correlations is that the rate of each mode of uptake is proportional to membrane area.

The rapid onset ( $<60 \mathrm{~s}$ ) of $\mathrm{Etd}^{+}$uptake evoked by BzATP suggests that $\mathrm{P} 2 \mathrm{X}_{7} \mathrm{R}$ and $\mathrm{Px} 1$ are in the surface membrane at the time of BzATP application. 

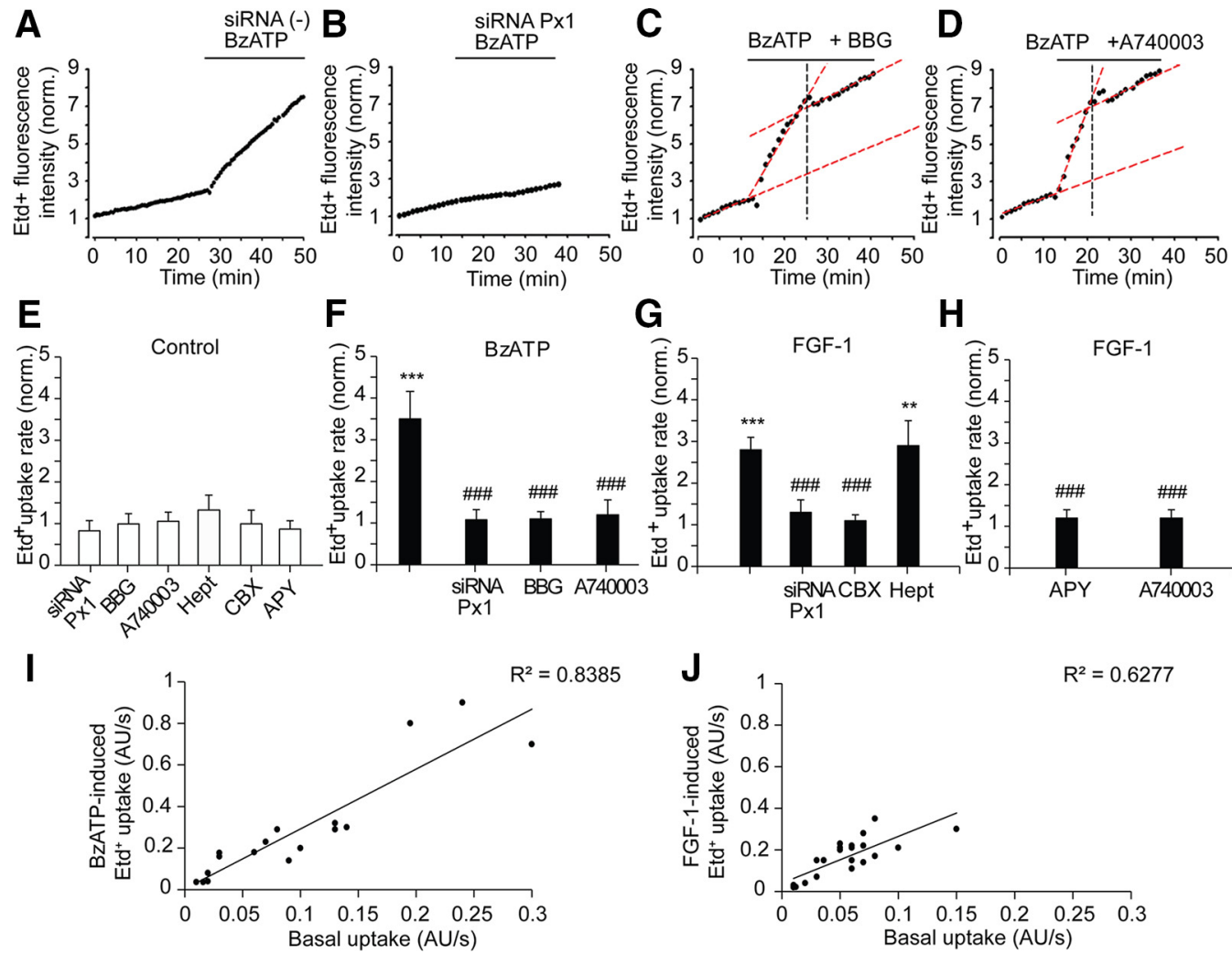

Figure 4. Increases in Etd ${ }^{+}$permeability induced by BzATP and FGF-1 depend on activation of P2X 7 Rs and opening of Px1 HCs. $A$, Permeability to Etd ${ }^{+}$was increased by BzATP treatment $(35 \mu \mathrm{m})$ in $<60 \mathrm{~s}$. $\boldsymbol{B}$, In a cell in which Px1 had been knocked down by $24 \mathrm{~h}$ transfection with siRNA Px1, BzATP did not increase membrane permeability. $\boldsymbol{C}, \boldsymbol{D}$, Increase in

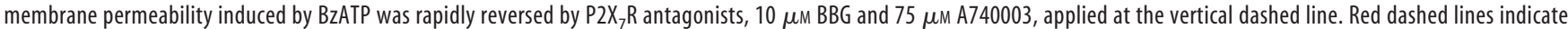

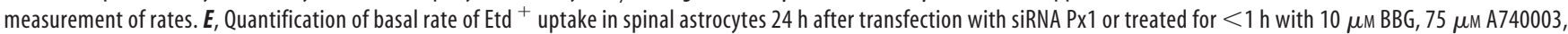
$0.7 \mathrm{~mm}$ heptanol (Hept), $200 \mu \mathrm{m}$ CBX, and $2 \mathrm{mU} / \mathrm{ml}$ APY. The rates of Etd ${ }^{+}$uptake in cells treated with siRNA Px1, BBG, A740003, heptanol, CBX, and APY were not significantly different from the basal uptake in control. $\boldsymbol{F}$, Quantification for experiments represented in $\boldsymbol{A}-\boldsymbol{D}$. $\mathbf{G}$, Quantification for experiments like those shown in Figure $3 A$. Permeability to Etd ${ }^{+}$was increased by FGF-1 treatment within 5-10 min. In cells in which Px1 was knocked down by $24 \mathrm{~h}$ transfection with siRNA, FGF-1 did not increase uptake. Increase in membrane permeability induced by FGF-1 was also reversed by $200 \mu \mathrm{M}$ CBX but not by $0.7 \mathrm{~mm}$ heptanol. $\boldsymbol{H}$, In cells treated with APY (2 mU/ml) or A740003 (75 $\mu \mathrm{M})$ before and during FGF-1 application, Etd ${ }^{+}$uptake rates were little affected by FGF-1. $n=4-7$. ${ }^{* *} p<0.01$ versus control. ${ }^{* * *} p<0.001$ versus control. ${ }^{\# \# \#} p<0.001$ versus BzATP or FGF- 1 alone. I, J, Basal uptake was correlated with BzATP-induced $(\boldsymbol{I})$ and FGF-1-induced $(\boldsymbol{J})$ uptake. $n=3-7 . R^{2}=0.8385$, BzATP versus basal uptake. $R^{2}=0.6277$, FGF-1 versus basal uptake.

\section{Self-sustained ATP release and $\mathrm{P} 2 \mathrm{X}_{7} \mathrm{R}$ activation maintain elevated membrane permeability to Etd ${ }^{+}$}

FGF-1 is likely released from cells damaged in spinal cord injury. However, FGF-1 is unstable at physiological temperatures and will not remain active for long time at a site of injury in vivo (half-life $<2$ h) (Lee and Blaber, 2009; Zakrzewska et al., 2009; Xia et al., 2012). We tested the duration of FGF-1-induced increase in membrane permeability by washing off FGF-1 with heparin after 2 or $4 \mathrm{~h}$ and applying Etd ${ }^{+}$for $10 \mathrm{~min}$ at $7 \mathrm{~h}$. After 2 or $4 \mathrm{~h}$ treatment, Etd ${ }^{+}$uptake at $7 \mathrm{~h}$ was higher than control (Fig. $5 A-C)$. A possible mechanism of the maintained process is that the initial vesicular release of ATP activates $\mathrm{P}_{2} \mathrm{X}_{7}$ Rs to open Px1 HCs, which leads to a further release of ATP (Pelegrin and Surprenant, 2006; Locovei et al., 2007). The washout of FGF-1 would also remove ATP, but the HCs may remain open long enough to replenish the ATP. Furthermore, FGF-1 also opens Cx43 HCs (to release ATP), but with a greater delay and possibly by a different mechanism (Garré et al., 2010). For 2 and 4 h FGF-1 treatment, $\mathrm{Etd}^{+}$uptake at $7 \mathrm{~h}$ was increased $\sim 2.3$ and 3.1 times basal, respectively ( $p<0.052 \mathrm{~h}$ vs basal, $p<0.0014 \mathrm{~h}$ vs basal, $n=4$ ); for $4 \mathrm{~h}$, values were not significantly less than that after $7 \mathrm{~h} \mathrm{FGF-1}$ ( $p<0.001$ vs basal, $p>0.05$ vs 4 h FGF-1; Fig. $5 C$ ). Application of $2 \mathrm{mU} / \mathrm{ml}$ APY during the last 15 min of FGF-1 treatment for 4 and $7 \mathrm{~h}$ and continuing through recording significantly reduced the increase in uptake ( $p<0.001$ vs FGF- 1 alone, $n=4$ ). Application of APY without FGF- 1 for the same periods of time did not change uptake ( $1.00 \pm 0.05$ times basal, $p>0.05$ vs basal). There was a small but significant increase induced by 4 and 7 h FGF-1 application that was not prevented by APY (Fig. 5C), which may be attributed to an FGFR effect independent of ATP, such as opening of Cx43 HCs.

As noted above (Fig. 4), P2 $\mathrm{X}_{7} \mathrm{R}$ activation is an early event underlying the increase in $\mathrm{Etd}^{+}$permeability induced by FGF-1. To investigate whether $\mathrm{P}_{2} \mathrm{X}_{7} \mathrm{Rs}$ also contribute to the long-term self-maintaining response as proposed, we measured the effect of A740003 on rates of Etd ${ }^{+}$uptake at $7 \mathrm{~h}$ after onset of 4 or $7 \mathrm{~h}$ FGF-1 treatment. Similar to the results obtained with APY, treatment with A740003 (75 $\mu \mathrm{M}$ applied $15 \mathrm{~min}$ before the end of 4 or $7 \mathrm{~h}$ FGF-1 treatment and continuing through recording) reduced the increase in $\mathrm{Etd}^{+}$uptake to $\sim 1.6$ times basal $(4 \mathrm{~h}: p<0.01$ vs FGF-1, 7 h: $p<0.001$ vs FGF- $1, p<0.05$ vs basal, $n=5$; Fig. $5 C$ ). Rates were normalized to their respective controls (FGF-1 to control, FGF-1 + APY to APY alone, FGF-1 + A740003 to A740003 alone).

In addition to the increase in $\mathrm{Etd}^{+}$uptake at $7 \mathrm{~h}$ after 2, 4, or 7 h FGF-1 application, $\left[\mathrm{Ca}^{2+}\right]_{\mathrm{i}}$ was elevated. For all three durations, the $\left[\mathrm{Ca}^{2+}\right]_{\mathrm{i}}$ levels were not significantly different from each other ( $p<0.05$ vs basal, $n=4$; Fig. $5 D)$. 
A

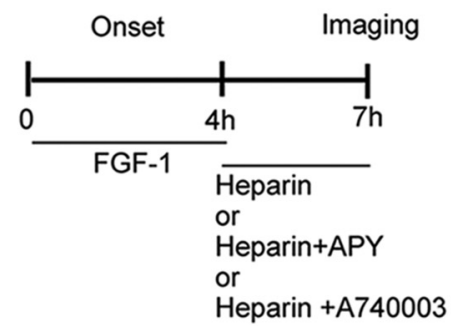

B

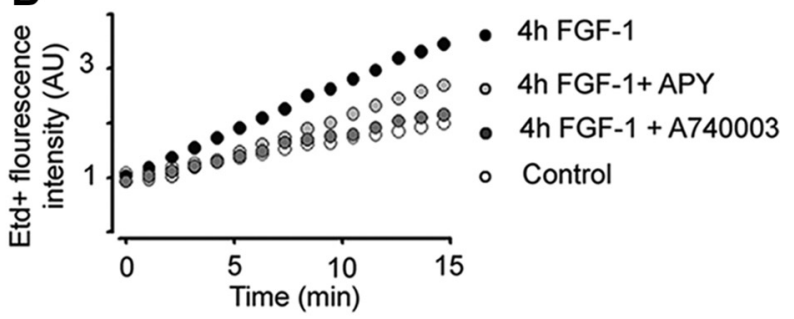

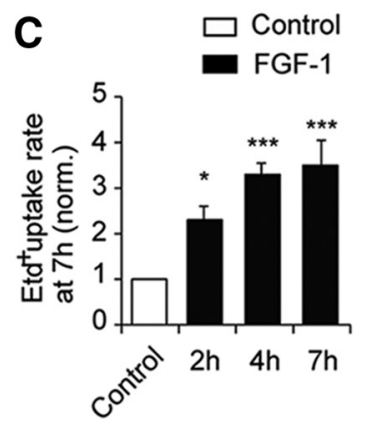
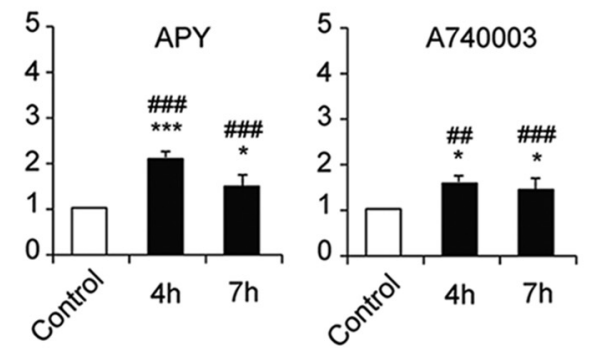

D

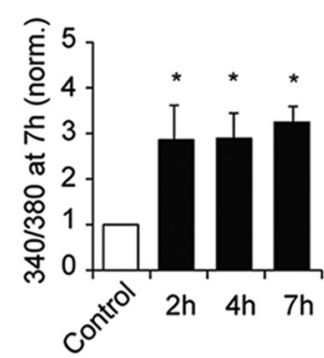

Figure 5. ATP-induced ATP release and P2X $\mathrm{X}_{7}$ activation maintain elevated membrane permeability to Etd ${ }^{+}$during spinal astrocyte activation with FGF-1. A, Diagram illustrating the experimental procedure. Etd ${ }^{+}$uptake in spinal astrocytes was evaluated $7 \mathrm{~h}$ after start of FGF- 1 treatment, which lasted $2 \mathrm{~h}, 4 \mathrm{~h}$ (shown in the diagram), or $7 \mathrm{~h}$ followed by washout with vehicle (heparin). To evaluate APY or A740003 effect on Etd ${ }^{+}$uptake, both drugs were applied starting 15 min before the end of FGF- 1 application and continuing until the end of Etd ${ }^{+}$ uptake measurement. B, FGF-1 stimulation for $4 \mathrm{~h}$ increased uptake at $7 \mathrm{~h}$ (filled circles). Uptake was reduced by application of APY (light gray circles) or A740003 (dark gray circles). C,

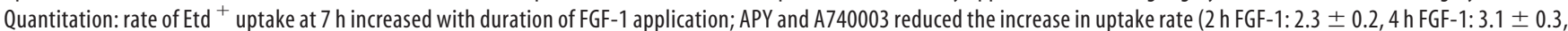

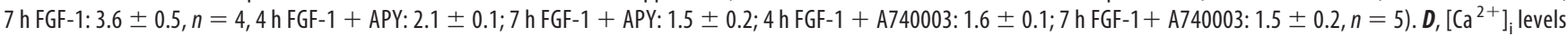
at $7 \mathrm{~h}$ were elevated after 2,4 , and $7 \mathrm{~h} \mathrm{FGF-1}$ application as in C ( $2 \mathrm{~h}: 2.8 \pm 0.8,4 \mathrm{h:} 2.8 \pm 0.6,7 \mathrm{~h}: 3.1 \pm 0.3, p<0.05$ vs control, $n=4) .{ }^{*} p<0.05$ versus control. ${ }^{* * *} p<0.001$ versus control. ${ }^{\# \#} p<0.01$ versus 4 or $7 \mathrm{~h} \mathrm{FGF-1}$ alone. ${ }^{\# \#} p<0.001$ versus 4 or $7 \mathrm{~h} \mathrm{FGF-1}$ alone.

Together, these data from cultures of spinal astrocytes suggest that, after an initial FGF-1-induced $\mathrm{Ca}^{2+}$-dependent vesicular release of ATP, $\mathrm{P}_{2} \mathrm{X}_{7} \mathrm{Rs}$ activate $\mathrm{Px} 1 \mathrm{HCs}$, which mediate efflux of ATP that acts back on the $\mathrm{P}_{2} \mathrm{X}_{7} \mathrm{Rs}$, and that at longer times there is an additional contribution, possibly from opening of $\mathrm{Cx} 43$ HCs.

FGF-1 increases astrocyte membrane permeability to $\mathrm{Etd}^{+}$in spinal cord slices ex vivo

As shown in Figures 3-5, time lapse imaging of $\mathrm{Etd}^{+}$uptake in cultures offers a sensitive method to quantify rapid changes $(<2$ $\mathrm{min}$ ) in membrane permeability caused by $\mathrm{HC}$ opening. Alternatively, it is possible to quantify cumulative $\mathrm{Etd}^{+}$uptake during a fixed period of $\mathrm{Etd}^{+}$application. We quantified $\mathrm{Etd}^{+}$uptake after 10 min application (Abudara et al., 2015) to determine whether FGF-1 regulates HC activity in acute slices of spinal cord in the same way it does in cultures of spinal astrocytes. We also tested acute cortical slices to determine whether, as in cultures of cortical astrocytes, FGF-1 had no effect on Etd ${ }^{+}$uptake (Garré et al., 2010).

$\mathrm{Etd}^{+}$uptake was measured in gray matter astrocytes identified by immunolabeling of GFAP. Microglia were readily identified throughout gray and white matter by EGFP expression in $\mathrm{CX}_{3} \mathrm{CR} 1^{\mathrm{EGFP}}$ mice (Fig. $6 \mathrm{~A}$ ). $\mathrm{Etd}^{+}$uptake over $10 \mathrm{~min}$ in living cells was calibrated in a fluorescence range from $0-255 \mathrm{AU} . \mathrm{F}_{\text {min }}$ corresponded to the background level, and $\mathrm{F}_{\max }$ (the maximum fluorescence in the image) was set at $255 \mathrm{AU}$. Astrocytes in spinal cord (but not cortical) slices treated with FGF-1 for $1 \mathrm{~h}$, showed accumulation of $\mathrm{Etd}^{+}$over 10 min that was $\sim 56 \%$ greater than that observed in control slices (control: $75.0 \pm 3$ AU, FGF-1: $117 \pm 4 \mathrm{AU}, p<0.001$ vs control, 300 astrocytes, $n=7$ slices; Fig. $6 B)$. The $\mathrm{Etd}^{+}$uptake in astrocytes was heterogeneous in both control slices and slices treated with FGF-1 (SDs were 30 and 49
AU in control and FGF-1-treated slices, respectively; Fig. 6B). The percentage of cells showing high $\mathrm{Etd}^{+}$uptake was defined as the percentage of cells showing $\mathrm{Etd}^{+}$fluorescence $\geq 1$ SDs above the mean in control slices ( $\geq 105 \mathrm{AU}, n=330$ astrocytes, $p<0.0001$ FGF-1 vs control, $\chi^{2}$ test; Fig. 6). The fraction of high $\mathrm{Etd}^{+}$astrocytes was increased in spinal cord slices treated with FGF-1 ( $p<0.01$, FGF-1 vs control, 300 astrocytes, $n=7$ slices; Fig. $7 A$ ). In accordance with our previous observation in cultured cortical astrocytes (Garré et al., 2010), FGF-1 did not increase $\mathrm{Etd}^{+}$uptake by astrocytes in cortical slices (control: $76.1 \pm 3.0$ AU, FGF-1: $80.0 \pm 8.0 \mathrm{AU}, p>0.05$ vs control, 200 astrocytes, $n=4$ slices; Fig. $6 C$ ). Microglia in both spinal and cortical slices took up $\mathrm{Etd}^{+}$under basal conditions, and the mean uptake in these cells was not changed by $1 \mathrm{~h}$ of FGF-1 treatment of tissue from either region (control: $89.5 \pm 5.5 \mathrm{AU}$ and $96.0 \pm 9.0 \mathrm{AU}$ and FGF-1: $104.4 \pm 11.2 \mathrm{AU}, 94.0 \pm 9.0 \mathrm{AU}$, spinal and cortical slices, respectively, $p>0.05$ FGF-1 vs control, 200-300 microglia, $n=7$ slices; Fig. $6 D, E)$. Thus, FGF-1 induces increase in $\mathrm{Etd}^{+}$uptake by spinal astrocytes, and it has little, if any, effect on cortical astrocytes or on spinal or cortical microglia.

\section{Dye uptake induced by FGF-1 in astrocytes in spinal cord} slices ex vivo depends on intracellular calcium signaling and $\mathrm{P} 2 \mathrm{X}_{7} \mathrm{R}$ activation

To study the contribution of intracellular calcium signaling to the changes in $\mathrm{Etd}^{+}$uptake induced by FGF-1 in astrocytes in spinal cord slices, we pretreated slices with U73122 or BAPTA-AM and quantified Etd ${ }^{+}$uptake after $1 \mathrm{~h}$ of FGF-1 treatment. The percentage of high Etd ${ }^{+}$astrocytes was $22.0 \pm 5.0 \%$ in control (250 astrocytes, $n=6$ slices) and $50.0 \pm 10.0 \%$ after 1 h FGF- 1 treatment (330 astrocytes, $n=7$ slices, $p<0.01$ FGF- 1 vs control; Fig. $7 A)$. The fraction of high Etd ${ }^{+}$astrocytes after FGF-1 treatment was significantly reduced by pretreatment with U73122 (4 $\mu \mathrm{M}$, 
A
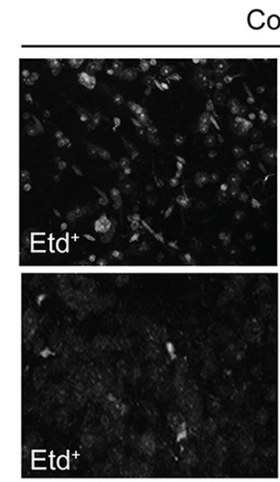

B
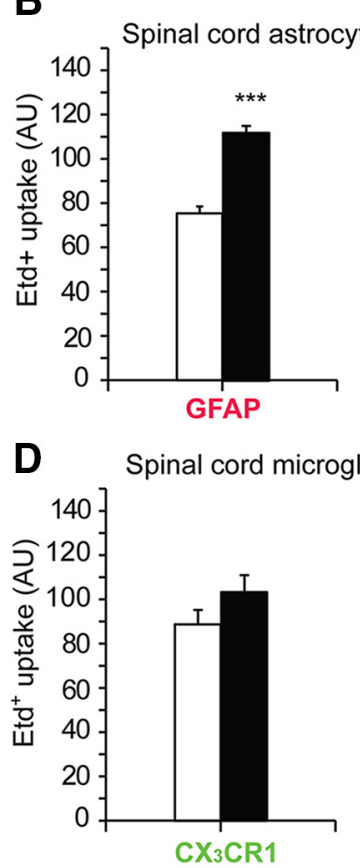

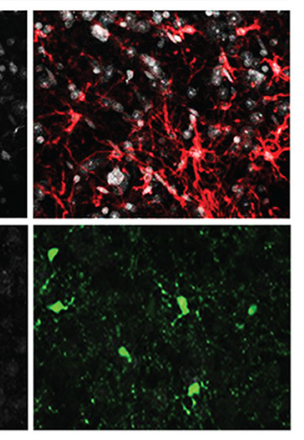

Control

$\square$ Control
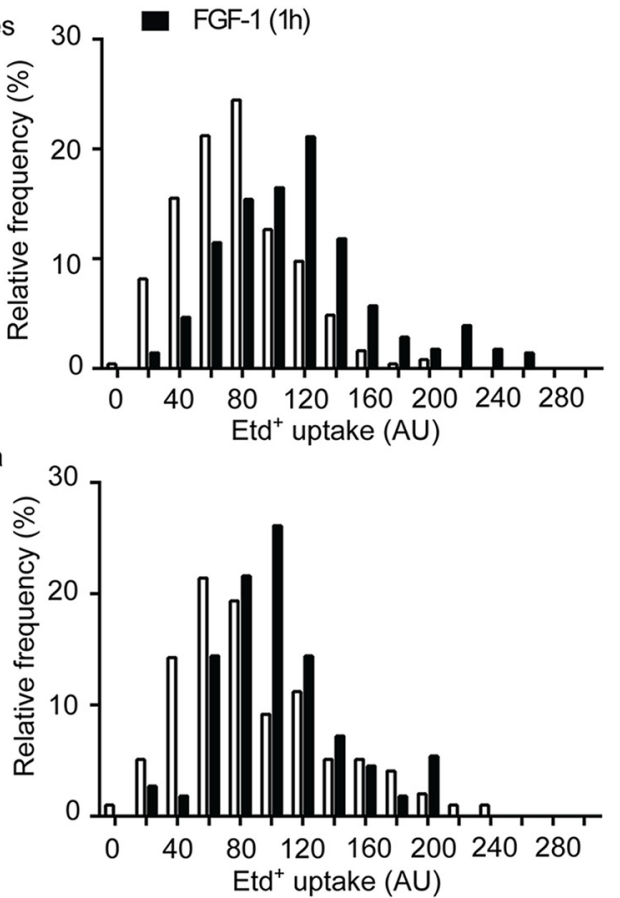

FGF-1 (1h)

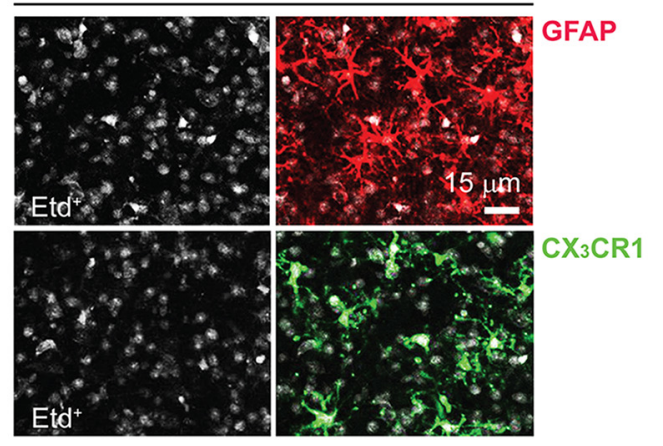

C

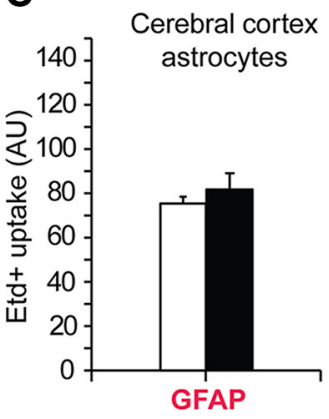

E Cerebral cortex

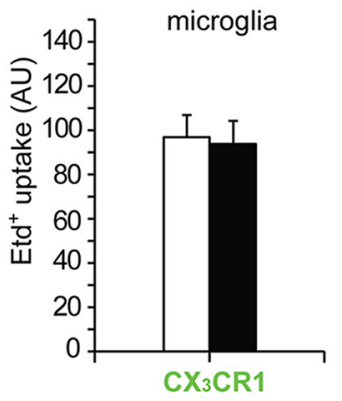

Figure 6. FGF-1 increases Etd ${ }^{+}$uptake by astrocytes in spinal cord but not cortical slices; FGF-1 does not affect Etd ${ }^{+}$uptake by microglia in slices from either region. $A$, Microphotographs of dorsal gray matter in spinal cord slices under control conditions (left panels) or treated with FGF-1(right panels) for $1 \mathrm{~h}$. Etd ${ }^{+}$fluorescence (gray) with GFAP immunolabeling of astrocytes (red) and $\mathrm{CX}_{3} \mathrm{CR}_{1}{ }^{\mathrm{EGFP}}$ expression in microglia (green). Etd ${ }^{+}$was applied for $10 \mathrm{~min}$, and slices were fixed for $2 \mathrm{~h}$ in PFA. FGF-1 increased GFAP labeling and activated microglia. Scale bar, $15 \mu \mathrm{m}$. B, FGF-1 increased Etd ${ }^{+}$uptake by astrocytes in spinal cord slices. Mean Etd ${ }^{+}$uptake and distribution histograms of Etd ${ }^{+}$uptake in GFAP ${ }^{+}$astrocytes in acute spinal cord slices, control or treated with FGF-1 for 1 h. C, FGF-1 treatment for $1 \mathrm{~h}$ did not affect Etd ${ }^{+}$uptake by astrocytes in slices of cerebral cortex. D, E, FGF-1 did not affect Etd ${ }^{+}$uptake by microglia in slices of spinal cord or cerebral cortex. D, FGF-1 did not increase mean and distribution histograms of Etd ${ }^{+}$uptake by microglia in acute spinal cord slices. $E$, Mean Etd ${ }^{+}$uptake in $C X_{3} C R 1^{+}$cells in acute cerebral cortex slices, control or treated with FGF-1 for 1 h. $n=4-7 .{ }^{* * *} p<0.001$ versus control (Mann-Whitney unpaired test). $\boldsymbol{B}, p<0.0001$ for histograms $\left(\chi^{2}\right.$ test, $\left.1 \mathrm{df}\right)$.

$p<0.05$ vs FGF- 1$)$ and BAPTA-AM $(1 \mu \mathrm{M}, p<0.05$ vs FGF- 1$)$. $\mathrm{U} 73343(4 \mu \mathrm{M})$, the inactive isoform, did not change the frequency of high Etd ${ }^{+}$astrocytes in control or FGF-1-treated slices ( $p<0.05$ control vs FGF-1, 250 cells, $n=6$ slices). This increase in the percentage of astrocytes with enhanced $\mathrm{Etd}^{+}$uptake also depended on ATP release because ATP hydrolysis with APY (2 $\mathrm{mU} / \mathrm{ml}$ ) markedly reduced the frequency of high $\mathrm{Etd}^{+}$astrocytes, to $10.0 \pm 8.0 \%$ ( $p<0.05$ vs FGF-1, 250 astrocytes, $n=5$ slices). BAPTA-AM, U73122, and U73343 ( $4 \mu \mathrm{M})$ were applied 15 min before the end of the FGF-1 treatment and remained during the entire period of $\mathrm{Etd}^{+}$uptake measurement. APY was applied 15 min before, during FGF-1 treatment, and during Etd ${ }^{+}$ uptake measurement. The same period of treatment with these drugs did not affect the number of high $\mathrm{Etd}^{+}$astrocytes in control slices ( $p>0.05$ vs control, $n=6-10$ slices; Fig. $7 A$ ).

To analyze the contribution of $\mathrm{P}_{2} \mathrm{X}_{7} \mathrm{Rs}$ to increase in $\mathrm{Etd}^{+}$ uptake by astrocytes in spinal cord, we used the same pharmaco- logical tools applied to cultured spinal astrocytes, namely, two potent $\mathrm{P} 2 \mathrm{X}_{7} \mathrm{R}$ antagonists, $\mathrm{A} 740003$ and BBG, and RB2, a nonselective $\mathrm{P} 2 \mathrm{Y}$ and $\mathrm{P} 2 \mathrm{X}$ receptor antagonist with little effect on $\mathrm{P} 2 \mathrm{X}_{7}$ Rs (Fisher et al., 2009). The fraction of high Etd ${ }^{+}$astrocytes was comparable in control and in slices treated with any of these 3 blockers for $\sim 1 \mathrm{~h}$ (250 astrocytes, $p>0.05, n=5$ slices, A740003 or BBG or RB2 vs control; Fig. $7 B-D)$. The fraction of high Etd ${ }^{+}$astrocytes after $1 \mathrm{~h} \mathrm{FGF-1} \mathrm{treatment} \mathrm{was} \mathrm{significantly}$ decreased by pretreatment with $0.1,1,10$, and $100 \mu \mathrm{M}$ A740003 ( $p>0.05$ vs control, $p<0.05$ vs FGF- 1 alone, 250 astrocytes, $n=$ 4 slices; Fig. $7 B$ ). BBG also reduced the percentage of high $\mathrm{Etd}^{+}$ astrocytes after FGF-1 treatment; the effect was dose-dependent and near maximal at concentrations of $\geq 1 \mu \mathrm{M}(p<0.05$ vs control, $p>0.05$ vs FGF- 1 alone at $0.1 \mu \mathrm{M} ; p>0.05$ vs control, $p<0.05$ vs FGF- 1 alone at $1-100 \mu \mathrm{M}, 250$ astrocytes, $n=6$ slices; Fig. $7 C$ ). In contrast, RB2 had no effect at $0.1-1 \mu \mathrm{M}$, a modest effect at $10 \mu \mathrm{M}$, and inhibited the response at $100 \mu \mathrm{M}(p<0.01 \mathrm{vs}$ 

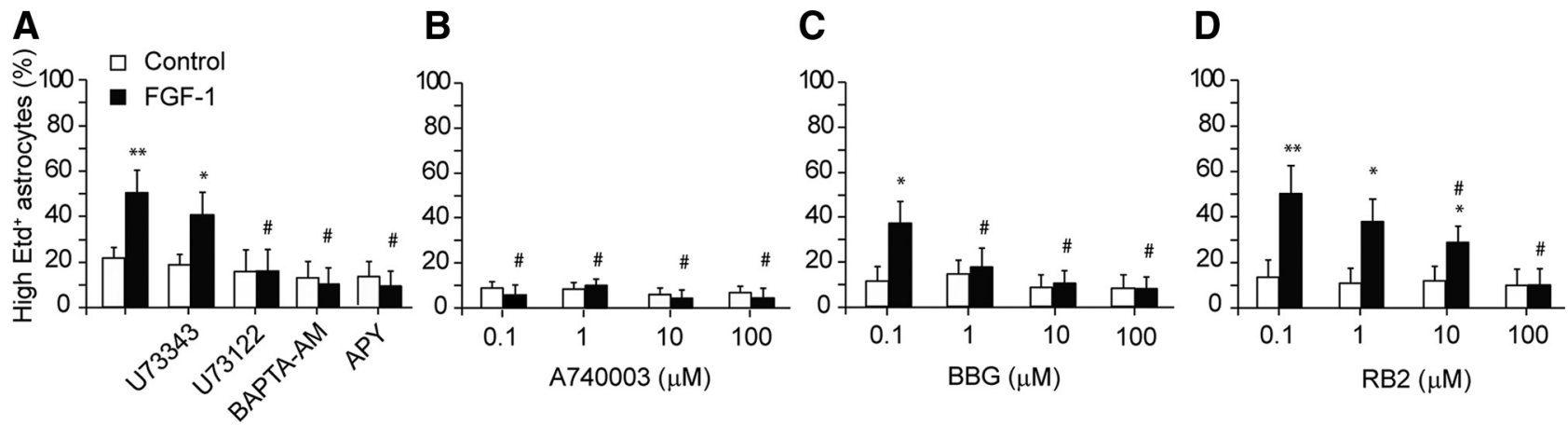

Figure 7. FGF-1-induced Etd ${ }^{+}$uptake in astrocytes in spinal cord slices depends on PLC, intracellular calcium signaling, ATP release, and P2X $\mathrm{R}_{7}$ activation. $\boldsymbol{A}_{\text {, Percentage of high Etd }}{ }^{+}$cells in

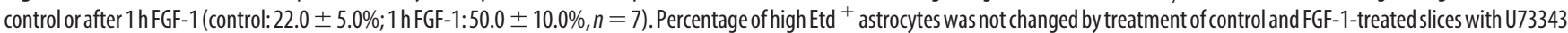
$(1 \mu \mathrm{M})$. In contrast, U73122 (1 $\mu \mathrm{M})$, BAPTA-AM $(4 \mu \mathrm{M})$, and APY ( $2 \mathrm{mU} / \mathrm{ml})$ blocked FGF-1-induced uptake, although they did not affect percentage of high Etd ${ }^{+}$cells in control conditions (control and FGF-1, respectively: U73343: $19.0 \pm 4.0 \%, 40.5 \pm 9.0 \%$; U73122: $16.0 \pm 8.3 \%, 16.0 \pm 8.0 \%$, BAPTA-AM: $12.0 \pm 8.0 \%, 10.0 \pm 8.0 \%$; APY: $12.0 \pm 7.0 \%, 9.7 \pm 6.0 \%$, control and FGF-1, respectively, $n=6$ ). $\boldsymbol{B}$, The percentage of high Etd ${ }^{+}$astrocytes was not changed in control or by FGF-1 in slices treated with $0.1,1,10$, and $100 \mu \mathrm{M} \mathrm{of} \mathrm{A740003} \mathrm{(Control} 0.1-100 \mu \mathrm{m}: 9.8 \pm 2.5 \%$, $\left.9.0 \pm 2.3 \%, 5.0 \pm 4.0 \%, 5.0 \pm 2.0 \% ; F_{G F-1} .1-100 \mu \mathrm{m}: 6.0 \pm 5.0 \%, 10.0 \pm 2.3 \%, 5.1 \pm 4.0 \%, 3.0 \pm 2.0 \%, n=4, \boldsymbol{B}\right)$. C, Treatment with BBG at 0.1 to $100 \mu \mathrm{m} \mathrm{did} \mathrm{not} \mathrm{affect} \mathrm{control} \mathrm{uptake} \mathrm{and}$

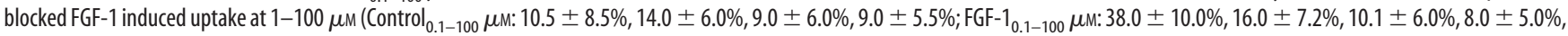
$n=6, C$. D, At the same concentrations as for BBG, RB2 did not affect control uptake and significantly reduced uptake at 10 and $100 \mu \mathrm{m}$ (Control $0_{0.1-100} \mu \mathrm{m}: 12.0 \pm 9.0 \%, 10.0 \pm 8.5 \%, 11.0 \pm$ $8.5 \%, 10.3 \pm 8.0 \%$; FGF-1 $\left.{ }_{0.1-100} \mu \mathrm{m}: 50.8 \pm 11.0 \%, 38.0 \pm 11.0 \%, 29.8 \pm 6.0 \%, 10.0 \pm 8.0 \%\right)$. The blockers and apyrase were applied $10-15$ min before vehicle or FGF- 1 treatment, and left until EtdBr incubation was terminated (1.25 h total period of treatment). $n=5-7 .{ }^{*} p<0.05$ versus control. ${ }^{* *} p<0.05$ versus control. ${ }^{*} p<0.05$ versus FGF-1.

\section{A}

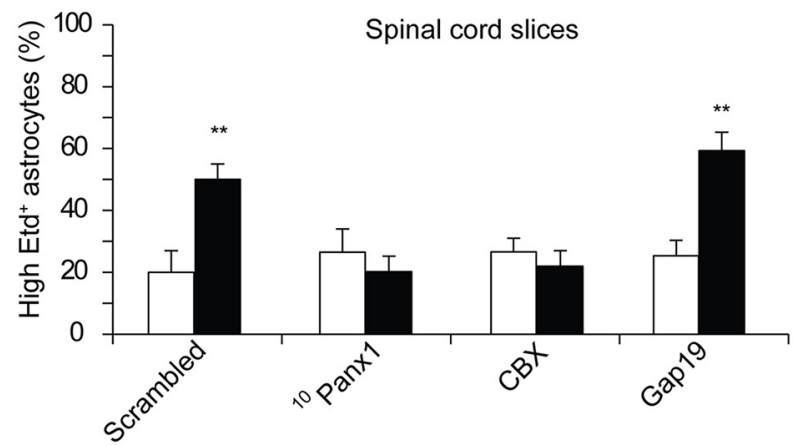

B

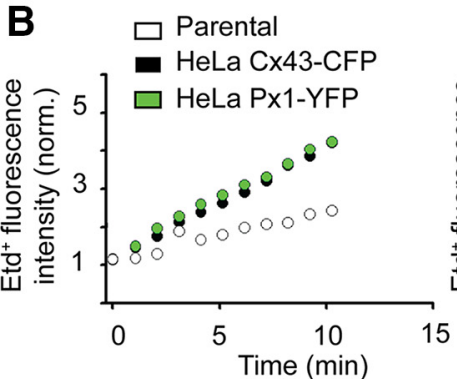

E

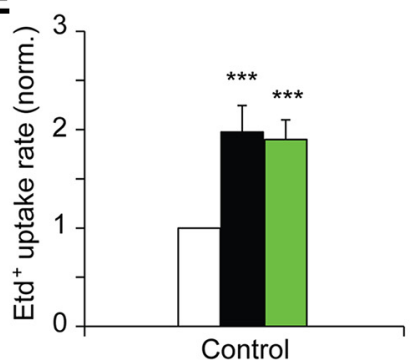

C
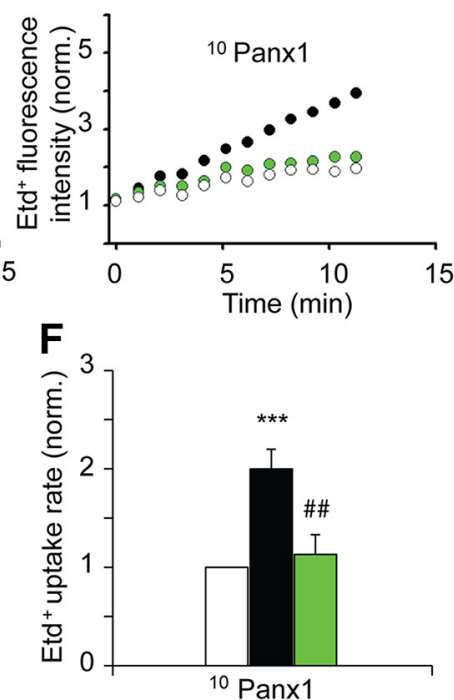

D

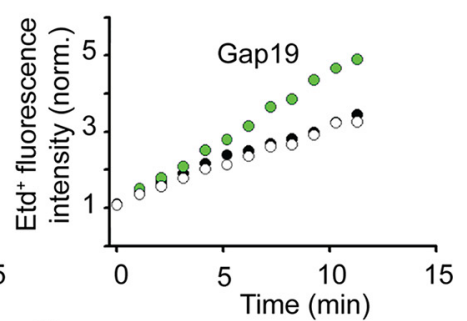

G

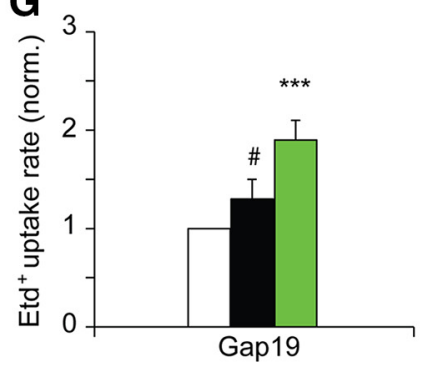

Figure 8. FGF-1-induced Etd ${ }^{+}$uptake in astrocytes in spinal cord slices is mediated by Px1 HCs. $A$, The increase in the percentage of high Etd ${ }^{+}$astrocytes in spinal cord slices treated with FGF-1 for $1 \mathrm{~h}$ was prevented by treatment with $100 \mu \mathrm{M}{ }^{10} \mathrm{Panx} 1$ or $200 \mu \mathrm{M}$ CBX but not affected by treatment with scrambled ${ }^{10} \mathrm{Panx} 1$ or $100 \mu \mathrm{m}$ Gap 19 (scrambled ${ }^{10} \mathrm{Panx} 1: 20.0 \pm 9.0 \%$, scrambled

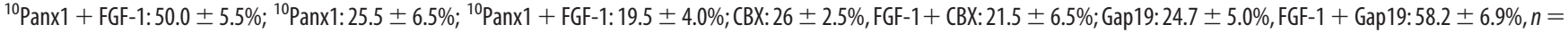
6 or 7 slices each condition). ${ }^{* *} p<0.01$ versus control. Blockers were applied $10-15$ min before vehicle or FGF-1 treatment and left until Etd ${ }^{+}$incubation was terminated (1.25 h total period of treatment). $\boldsymbol{B}-\mathbf{G}$, Specificity of inhibition by ${ }^{10} \mathrm{Panx} 1$ of Px1 HCs and by Gap 19 of $\mathrm{C} \times 43 \mathrm{HC}$. Time lapse imaging in mixed cultures of parental cells (open circles) and HeLa cells expressing Cx43-CFP (filled circles) and HeLa cells expressing Px1-YFP (green circles). B, E, HeLa CX43-CFP and HeLa Px1-YFP cells take up Etd ${ }^{+}$more rapidly than parental cells. C, F, Pretreatment with $100 \mu \mathrm{Mm}{ }^{10} \mathrm{Panx} 1$ reduced Etd ${ }^{+}$uptake rate in HeLa Px1-YFP cells but not in CX43-CFP cells. D, G, Pretreatment with $100 \mu \mathrm{m}$ Gap19 reduced Etd ${ }^{+}$uptake rate in HeLa Cx43-CFP cells but not in Px1-YFP cells. Blockers were applied $30-60 \mathrm{~min}$ before experiments and left during the Etd ${ }^{+}$uptake measurement (similar to $A, 0.75-1 \mathrm{~h}$ total period of treatment). $n=5 .{ }^{* * *} p<0.001$ versus parental. ${ }^{\#} p<0.05$ versus HeLa Cx43-CFP or HeLa Px1-YFP. ${ }^{\#} p<0.01$ versus HeLa Cx43-CFP or HeLa Px1-YFP. 

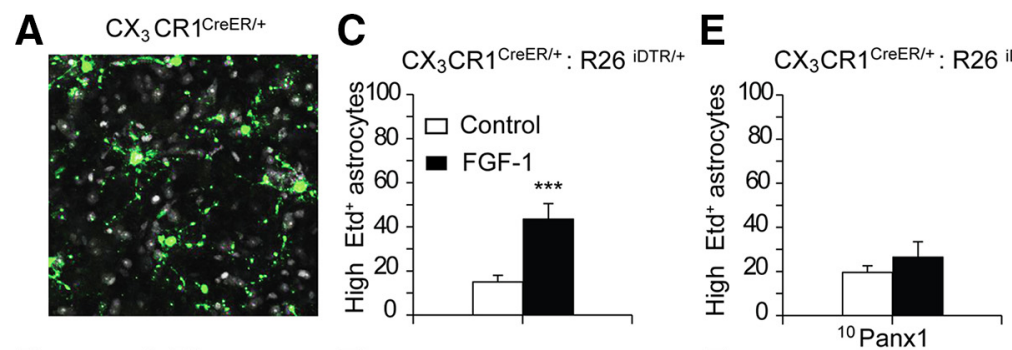

G
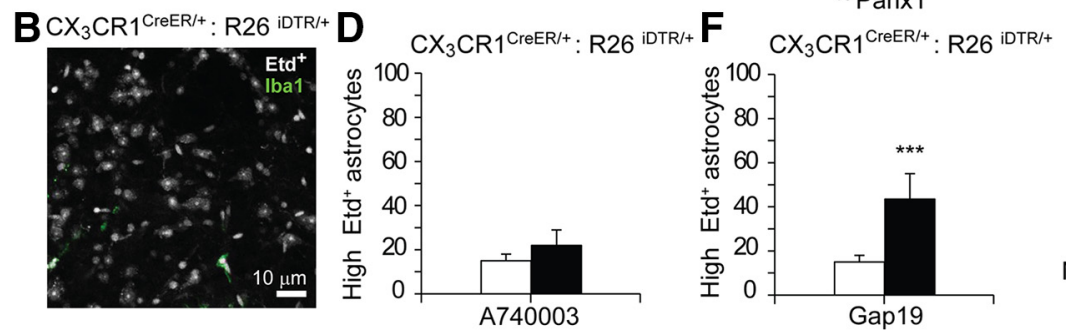

Microglia depletion

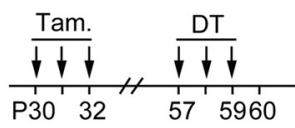

Spinal cord sectioning

(P60)

1h recovery

$\downarrow 1 \mathrm{~h}$ Hep. or FGF-1

10 min Etd ${ }^{+}$uptake

$$
\begin{aligned}
& 2 \mathrm{~h} \text { immersion } \\
& \text { of cord slices } \\
& \text { in PFA }
\end{aligned}
$$

Microglia immunostaining

Figure 9. Microglia are not required for FGF-1-induced Px1 HC opening in astrocytes in acute spinal cord slices. $A, B$, Cross-sections of spinal cord dorsal horn from CX $C$ CR1 1 reeE/+ control mice $(A)$

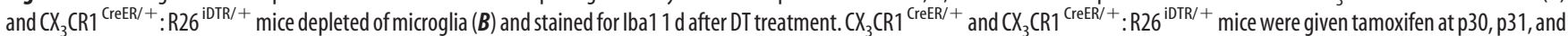
p32 and treated with DT at 20,21, and $22 \mathrm{~d}$ later. Iba1-positive cells were greatly depleted $24 \mathrm{~h}$ after DT treatment in $C X_{3} C R 1^{\text {CreER/+ }}:$ R2 $6^{\text {iDTR/+ }}$ mice $(B)$, but these were not affected in $\mathrm{CX}_{\mathrm{CR}} 1^{\mathrm{CreER} /+}$ mice $(\boldsymbol{A})$. Scale bar, $10 \mu \mathrm{m}$. $\left(-\boldsymbol{F}\right.$, FGF-1 significantly increased the percentage of high Etd ${ }^{+}$astrocytes in acute spinal cord slices that were depleted of microglia (C). This increase was prevented by pretreatment with $1 \mu \mathrm{MA}$ A740003 (D) or $100 \mu \mathrm{M}{ }^{10} \mathrm{Panx} 1(\boldsymbol{E})$, but not by $100 \mu \mathrm{m} \mathrm{Gap19}(\boldsymbol{F})$. Data values from $\mathrm{CX}_{3} \mathrm{CR}^{\mathrm{CreER} /+}: \mathrm{R}^{\mathrm{i}} 6^{\mathrm{iDTR} /+}$ mice depleted of microglia, control: $18.0 \pm$ 1.5\%, 1 h FGF-1: $44.0 \pm 6.0 \% ;$ A740003 + control: $16.1 \pm 3.2 \%$, A740003 + FGF-1: $20.0 \pm 9.0 \% ;{ }^{10}$ Panx 1 + control: $20.0 \pm 2.0 \%,{ }^{10}$ Panx1 + 1 h FGF-1: 28.2 $\pm 7.0 \%$; Gap 19 + control:

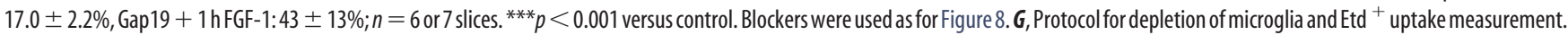

control, $p>0.05$ vs FGF-1 alone at $0.1 \mu \mathrm{M} ; p<0.05$ vs control, $p>0.05$ vs FGF- 1 alone at $1 \mu \mathrm{M} ; p<0.05$ vs control at $10 \mu \mathrm{M}, p>$ 0.05 vs control at $100 \mu \mathrm{M} ; p<0.05$ vs FGF- 1 at $10-100 \mu \mathrm{M}, 250$ astrocytes, $n=6$ slices; Fig. $7 D$ ). All reagents were applied $15 \mathrm{~min}$ before FGF-1 treatment and maintained until completion of $\mathrm{Etd}^{+}$uptake measurement. The reduction in the percentage of high $\mathrm{Etd}^{+}$astrocytes after FGF-1 treatment by A740003 and BBG, and by RB2 only at high concentrations, indicates that $\mathrm{P} 2 \mathrm{X}_{7} \mathrm{Rs}$ contributes to this response. A minor contribution from other types of purinergic receptor cannot be completely ruled out from our study.

FGF-1-induced Etd ${ }^{+}$uptake in astrocytes in acute spinal cord slices is mediated by Px1 HC opening

We used selective pharmacological tools to identify HC type in spinal cord slices. The increase in $\mathrm{Etd}^{+}$uptake by astrocytes in spinal cord slices treated with FGF-1 for $1 \mathrm{~h}$ was blocked by 100 $\mu \mathrm{M}{ }^{10} \mathrm{Panx} 1$, a synthetic peptide that selectively blocks Px1 HCs $\left(p>0.05,{ }^{10}\right.$ Panx $1+$ FGF-1 vs ${ }^{10}$ Panx $1, n=6$ slices; Fig. $\left.8 A\right)$ (Pelegrin and Surprenant, 2006). A scrambled version of ${ }^{10} \mathrm{Panx} 1$ did not affect the uptake in control slices and did not block the increase after $1 \mathrm{~h} \mathrm{FGF-1} \mathrm{treatment}(p<0.01$, scrambled + FGF-1 vs scrambled, 200 astrocytes, $n=6$; Fig. $8 A$ ). To further demonstrate that Px1 HC opening mediates FGF-1-induced Etd ${ }^{+}$uptake in astrocytes, we treated spinal cord slices with $200 \mu \mathrm{M} \mathrm{CBX}$, a GJ blocker that at this concentration inhibits both Px HCs and Cx HCs. In cells treated with CBX, there was no significant difference in the frequency of high Etd ${ }^{+}$astrocytes between control slices and slices treated with FGF-1 for $1 \mathrm{~h}(p>0.05$, FGF-1 + CBX vs CBX alone, 250 astrocytes, $n=6$; Fig. $8 A$ ).

Because, in cultured spinal astrocytes, $7 \mathrm{~h}$ but not $2 \mathrm{~h}$ FGF-1 treatment induces opening of $\mathrm{Cx} 43 \mathrm{HCs}$, we expected that $\mathrm{Cx} 43$ HCs would not contribute to increased membrane permeability after the $1 \mathrm{~h}$ FGF- 1 treatment when applied to spinal cord slices $e x$ vivo. In agreement the selective Cx43 HC blocker, Gap19 (100 $\mu \mathrm{M}$ ) (Abudara et al., 2014) did not alter the frequency of high Etd $^{+}$astrocytes after $1 \mathrm{~h} \mathrm{FGF-1} \mathrm{treatment}(p<0.01$, FGF-1 +
Gap19 vs Gap19 alone, $p>0.05$, FGF-1 + Gap19 vs FGF-1 alone, 300 astrocytes, $n=7$; Fig. $8 A$ ).

We confirmed the specificity of ${ }^{10} \mathrm{Panx} 1$ and Gap19 block of Pxl and Cx HCs, respectively, by applying these blockers to mixed cultures of parental (untransfected) HeLa cells, HeLa cells expressing Px1-YFP, and HeLa cells expressing Cx43-CFP (Fig. $8 B-G)$. The rate of $\mathrm{Etd}^{+}$uptake by HeLa Cx43-CFP cells was $2.0 \pm 0.3$ times that by parental cells $(p<0.001$ vs parental, $n=$ $5)$, similar to $\mathrm{Etd}^{+}$uptake rate by HeLa cells expressing Cx43EGFP (Contreras et al., 2003). The rate of $\mathrm{Etd}^{+}$uptake by HeLa Px1-YFP cells was $1.8 \pm 0.2$ times that by parental cells $(p<0.001$ vs parental, $n=5$; Fig. $8 B, E) .{ }^{10} \mathrm{Panxl}(100 \mu \mathrm{M})$ reduced the rate of Etd ${ }^{+}$uptake by HeLa Px1-YFP cells (to $1.1 \pm 0.3$ times parental, $p<0.01$ vs HeLa Px1-YFP without ${ }^{10} \mathrm{Panx} 1, p>0.05$ vs parental, $n=5$ ) and did not affect the rate of $\mathrm{Etd}^{+}$uptake by HeLa Cx43-CFP cells $(2.0 \pm 0.3$ times control, $p>0.05$ vs HeLa Cx43-CFP without ${ }^{10} \mathrm{Panx} 1, n=5$; Fig. $\left.8 C, F\right)$. In contrast, Gap 19 $(100 \mu \mathrm{M})$ reduced the rates of $\mathrm{Etd}^{+}$uptake in HeLa Cx43-CFP cells (to $1.3 \pm 0.2$ times control, $p<0.05$ vs HeLa Cx43-CFP without Gap19, $p>0.05$ vs parental) and had no significant effect on Px1-YFP cells $(1.8 \pm 0.3$ times control, $p>0.05$ vs HeLa Px1-YFP, $n=5$; Fig. $8 D, G)$. In these experiments, we treated HeLa cells with blockers for $0.5-1$ h before Etd ${ }^{+}$was applied to the bath, and continued the blockers during 10 min uptake recording.

These data suggest that the increase in percentage of high $\mathrm{Etd}^{+}$astrocytes in acute spinal cord slices after $1 \mathrm{~h}$ FGF- 1 treatment is mainly mediated by Px1 HCs.

\section{Microglia are not required for FGF-1-induced Etd ${ }^{+}$uptake in} spinal cord astrocytes

Two proinflammatory cytokines, TNF $\alpha$ and IL1- $\beta$, released by cortical microglia have been reported to increase $\mathrm{Cx} 43 \mathrm{HC}$ opening in astrocytes (Retamal et al., 2007). We prepared spinal cord slices from $\mathrm{CX}_{3} \mathrm{CR} 1^{\mathrm{CreER} /+} \mathrm{R} 26^{\mathrm{iDTR} /+}$ mice that had been depleted of microglia by treatment with tamoxifen and DT to investigate whether microglia contribute to the elevation of 
A

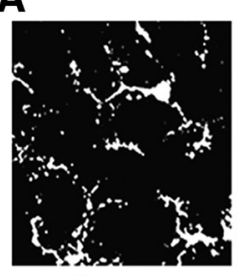

Control

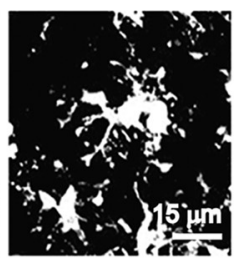

FGF-1 (1h)
B

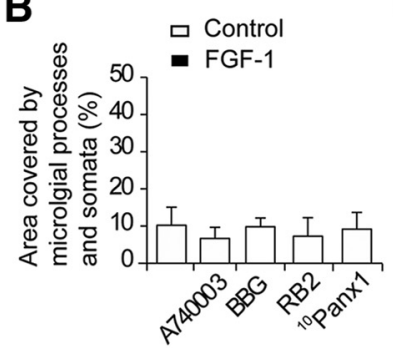

C

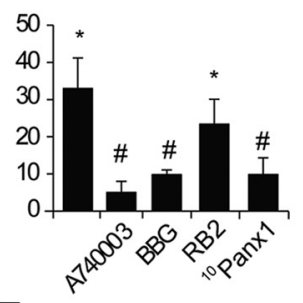

F TNF $\alpha$
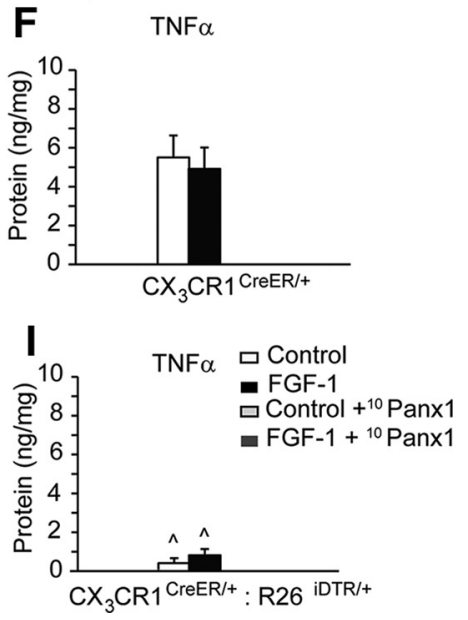

Figure 10. FGF-1 promotes inflammatory responses in acute spinal cord slices. A, Microglia show thin ramified processes $2 \mathrm{~h}$ after spinal cord sectioning (left). Morphological signs of microglial activation (shortening and thickening of processes, enlargement of somata) were enhanced after $1 \mathrm{~h}$ FGF-1 treatment in acute spinal cord slices. Slices were fixed in PFA $2 \mathrm{~h}$ after tissue sectioning. Scale bar, $15 \mu \mathrm{m}$. B, Percentage area covered by microglia somata and processes (z-axis projection) per $5000 \mu \mathrm{m}^{2}$ was not changed in slices treated with BBG (1-10 $\left.\mu \mathrm{m}\right)$, A740003 (1-10 $\mu \mathrm{M}$ ), ${ }^{10}$ Panx1 (100 $\left.\mu \mathrm{M}\right)$, or RB2 (1-10 $\left.\mu \mathrm{M}\right)$. Control: $10.0 \pm 5.2 \%$, A740003: $6.0 \pm 3.0 \%$, BBG: $9.5 \pm 2.0 \%$, RB2: $7.0 \pm 4.0 \%,{ }^{10}$ Panx1: $8.5 \pm 5.5 \%$; $n=4$ slices for each condition. C, FGF-1 increased the percentage area covered by microglia and their processes in acute spinal cord slices. This increase was prevented by A740003, BBG, and ${ }^{10}$ Panx 1 but was not affected by RB2; blockers were used at the same concentrations as in Cand applied as in Figures 7 and 8. FGF- 1 alone: $33.1 \pm 9.0 \%, A 740003: 5.0 \pm 3.0 \%, B B G: 10.0 \pm 1.0 \%$, RB2: $22.1 \pm 8 \%,{ }^{10}$ Panx1:9.2 $\pm 4.1 \% ; n=6$ slices each condition. ${ }^{*} p<0.05$ versus control. ${ }^{\#} p<0.05$ versus FGF-1. $\boldsymbol{D}-\boldsymbol{I}$, FGF-1 effects on levels of IL-1 $\beta(\boldsymbol{D}, \boldsymbol{G}), \mathrm{IL}-6(\boldsymbol{E}, \boldsymbol{H})$, and TNF $\alpha(\boldsymbol{F}, \boldsymbol{I})$ in spinal cord slices $2 \mathrm{~h}$ after preparation from control nondepleted ( $\boldsymbol{D}-\boldsymbol{F})$ or microglia depleted $(\boldsymbol{G}-\boldsymbol{I})$ mice. FGF-1 treatment ( $1 \mathrm{~h})$ of control, nondepleted slices increased IL-1 $\beta$ and IL-6 levels but did not affect TNF $\alpha$ level (IL-1 $\beta$, control: $0.30 \pm 0.03$ ng/mg, FGF-1: $0.50 \pm 0.10 \mathrm{ng} / \mathrm{mg} ; \mathrm{IL}-6$, control: $6.1 \pm 0.9 \mathrm{ng} / \mathrm{mg}$, FGF-1: $8.60 \pm 1.10 \mathrm{ng} / \mathrm{mg}$; TNF $\alpha$, control: $5.5 \pm 1.0 \mathrm{ng} / \mathrm{mg}, \mathrm{FGF}-1: 5.0 \pm 1.1 \mathrm{ng} / \mathrm{mg}, n=5 \mathrm{animals}) .{ }^{10} \mathrm{Panx} 1$ (100 $\left.\mu \mathrm{m}\right)$ prevented these increases in IL-1 $\beta$ and IL-6 (IL-1 $\beta$, control $+{ }^{10}$ Panx1:0.22 $\pm 0.09 \mathrm{ng} / \mathrm{mg}$, FGF-1 $+{ }^{10}$ Panx1:0.23 $\pm 0.10 \mathrm{ng} / \mathrm{mg} ; \mathrm{IL}-6$, control $+{ }^{10}$ Panx1:6.0 $\pm 1.0 \mathrm{ng} / \mathrm{mg}, \mathrm{FGF}-1+{ }^{10}$ Panx1: $5.2 \pm 1.0 \mathrm{ng} / \mathrm{mg}, n=4$ animals). Basal levels of IL-1 $\beta, \mathrm{IL}-6$, and TNF $\alpha$ were significantly reduced (markedly so for TNF $\alpha$ ) in slices depleted of microglia (IL-1 $\beta: 0.20 \pm 0.04 \mathrm{ng} / \mathrm{mg}, n=6$ animals, IL-6: $2.6 \pm 0.4 \mathrm{ng} / \mathrm{mg}, n=6$ animals, TNF $\alpha: 0.3 \pm 0.03 \mathrm{ng} / \mathrm{mg}, n=5$ animals). In depleted slices, FGF- 1 increased the production of IL-6 over control and did not affect the production of IL-1 $\beta$ or TNF $\alpha$ (IL-1 $\beta: 0.25 \pm 0.09 \mathrm{ng} / \mathrm{mg} ; \mathrm{IL}-6: 5.0 \pm 0.6 \mathrm{ng} / \mathrm{mg} ;$ TNF $\alpha: 0.46 \pm 0.25 \mathrm{ng} / \mathrm{mg} ; n=5$ or 6 animals). ${ }^{10}$ Panx1 (100 $\mu \mathrm{m}$ ) had little effect on levels of IL-1 $\beta$ in control and after FGF-1 treatment in slices depleted of microglia (IL-1 $\beta{ }^{10} \mathrm{Panx} 1$ alone: $0.21 \pm 0.08 \mathrm{ng} / \mathrm{mg}$, FGF- $1+{ }^{10} \mathrm{Panx} 1: 0.20 \pm 0.08 \mathrm{ng} / \mathrm{mg}$ ). ${ }^{10} \mathrm{Panx} 1 \mathrm{increased}$ the level of IL-6 in control depleted but not after FGF-1 treatment (IL-6 ${ }^{10}$ Panx1 alone: $4.5 \pm 0.6 \mathrm{ng} / \mathrm{mg}$, FGF- $1+{ }^{10} \mathrm{Panx} 1: 4.0 \pm 0.6 \mathrm{ng} / \mathrm{mg} ; n=4-6$ animals). ${ }^{*} p<0.05$ versus control nondepleted. ${ }^{\#} p<0.05$ versus FGF- 1 nondepleted. $\hat{p}<0.05$, control nondepleted versus control depleted or FGF-1 nondepleted versus FGF-1 depleted.

$\mathrm{Etd}^{+}$uptake by astrocytes induced by $1 \mathrm{~h}$ FGF-1 treatment. Nondepleted slices were prepared from $\mathrm{CX}_{3} \mathrm{CR} 1^{\mathrm{CreER} /+}$ mice treated with tamoxifen and DT and used as controls (Fig. 9A, B; see Materials and Methods) (Parkhurst et al., 2013). In spinal cord slices depleted of microglia (Fig. 9G), the percentages of high $\mathrm{Etd}^{+}$astrocytes in control or after $1 \mathrm{~h} \mathrm{FGF-1} \mathrm{treatment} \mathrm{were}$ not significantly different from those in control mice with intact microglia $\left(p>0.05, \mathrm{CX}_{3} \mathrm{CR} 1^{\mathrm{CreER} /+:} \mathrm{R} 26^{\mathrm{iDTR} /+}\right.$ vs $\left.\mathrm{CX}_{3} \mathrm{CR} 1^{\mathrm{CreER} /+}\right)$ or treated with FGF-1 $(p>0.05$, $\mathrm{CX}_{3} \mathrm{CR} 1^{\mathrm{CreER} /+:} \mathrm{R} 26^{\mathrm{iDTR} /+}+\mathrm{FGF}-1$ vs $\mathrm{CX}_{3} \mathrm{CR} 1^{\mathrm{CreER} /+}+$ FGF-1, 250 astrocytes, $n=6$ slices; Fig. 9C; for uptake in nondepleted slices, see Fig. 7A). In spinal cord slices depleted of microglia and treated with A740003 ( $1 \mu \mathrm{M})$, FGF-1 did not increase the percentage of astrocytes with enhanced $\mathrm{Etd}^{+}$uptake $(p>0.05$, $\mathrm{CX}_{3} \mathrm{CR} 1^{\mathrm{CreER} /+}: \mathrm{R} 26^{\mathrm{iDTR} /+}+\mathrm{FGF}-1$ vs $\mathrm{CX}_{3} \mathrm{CR} 1^{\mathrm{CreER} /+}$ : R2 $6^{\text {iDTR/+ }}, 250$ astrocytes, $n=7$; Fig. 9D). As expected, the percentage of high Etd ${ }^{+}$astrocytes after FGF-1 treatment was not increased in slices pretreated with $100 \mu \mathrm{M}{ }^{10} \mathrm{Panxl}(p>0.05$, $\mathrm{CX}_{3} \mathrm{CR} 1^{\mathrm{CreER} /+}: \mathrm{R}_{2} 6^{\mathrm{iDTR} /+}+\mathrm{FGF}-1$ vs $\mathrm{CX}_{3} \mathrm{CR} 1^{\mathrm{CreER} /+}$ : R2 $6^{\text {iDTR/+ }}, 200$ astrocytes, $n=6$; Fig. $9 E$ ). Conversely, pretreat- ment of these slices with $100 \mu \mathrm{M}$ Gap19 did not affect basal uptake, and the increase in high $\mathrm{Etd}^{+}$astrocytes induced by FGF-1 treatment $\left(p>0.05, \mathrm{CX}_{3} \mathrm{CR} 1^{\mathrm{CreER} /+}+\mathrm{FGF}-1\right.$ vs $\mathrm{CX}_{3} \mathrm{CR} 1^{\mathrm{CreER} /}$ $+: \mathrm{R} 26^{\mathrm{iDTR} /+}+$ FGF-1; Fig. $\left.9 F\right)$. These data indicate that, in the absence of microglia, $\mathrm{P} 2 \mathrm{X}_{7} \mathrm{Rs}$ and $\mathrm{Px} 1 \mathrm{HCs}$ expressed in astrocytes mediate FGF-1-induced increase in high $\mathrm{Etd}^{+}$astrocytes in acute spinal cord slices.

\section{FGF-1 promotes inflammatory responses in acute spinal cord slices}

To investigate whether activation of astrocyte $\mathrm{P}_{2} \mathrm{X}_{7}$ Rs and $\mathrm{Px} 1$ HCs subsequently induces microglial responses, we examined microglia in these slices for morphological changes (Fig. 10). In vivo studies in cerebral cortex reveal that microglia quickly respond to microinjuries by directing fine processes toward the site of injury through mechanisms that may involve ATP release through hemichannels in surrounding astrocytes and/or ATP release from damaged cells (Davalos et al., 2005). Furthermore, in acute cortical slices treated with glutamate, microglia rapidly increase the number of processes during early phases of activation 


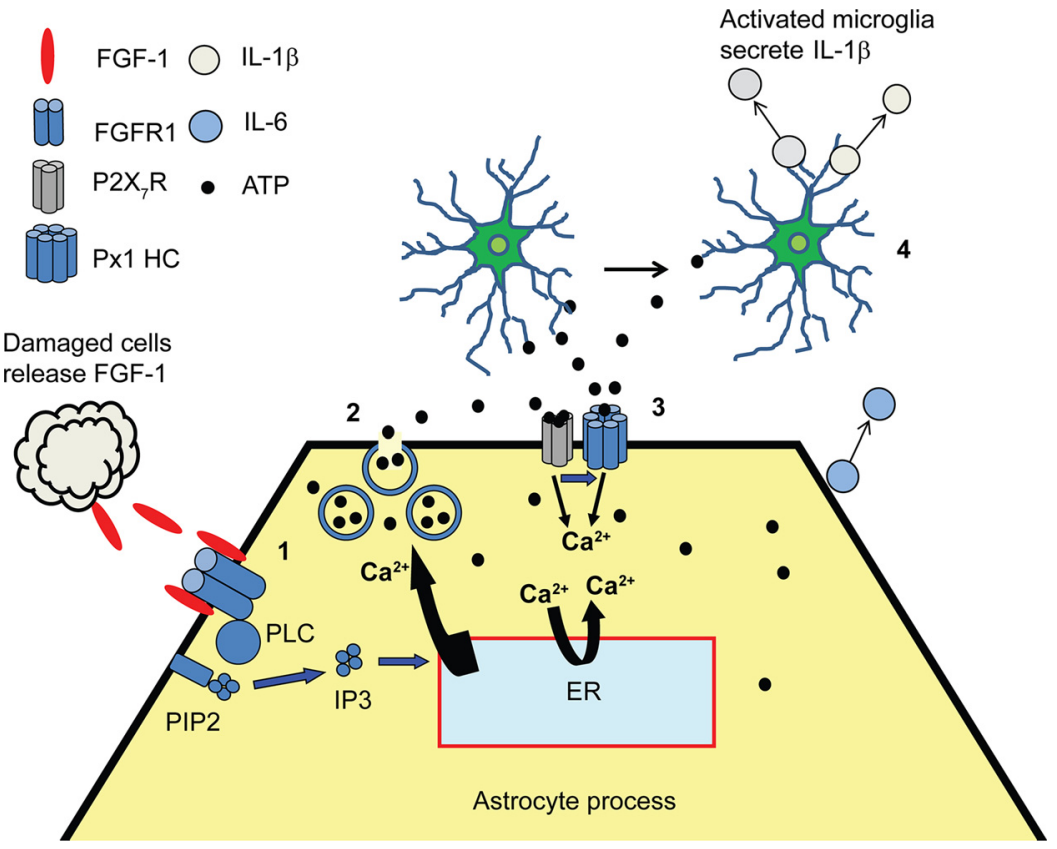

Figure 11. Schematic of early events by which FGF-1 activates proinflammatory responses in astrocytes and microglia. 1, FGF-1 released by damaged cells activates astrocyte FGFRs that increase PLC-mediated IP3 signaling and promotes the release of $\mathrm{Ca}^{2+}$ from the ER. 2, Rise in $\left[\mathrm{Ca}^{2+}\right]_{\mathrm{i}}$ induces vesicular secretion of ATP. 3, Secreted ATP activates P2X $\mathrm{X}_{7} \mathrm{Rs}$ in astrocytes that open Px1 HCs and promote additional release of ATP. IL-6 is presumably secreted from activated astrocytes. 4, ATP released from astrocytes activates microglia to secrete IL-1 $\beta$.

(Eyo et al., 2015). At the time we detected increased Px1 HC opening in astrocytes after FGF-1 treatment, microglial processes became thicker (Fig. 10A). The relative area covered by microglial processes in the $z$-axis projection increased from $10.0 \pm 5.2 \%$ in the control condition to $33.1 \pm 9.0 \%$ after $1 \mathrm{~h}$ FGF- 1 treatment $(p<0.01$ vs control, $n=6$; Fig. $10 B, C)$. FGF- 1 treatment did not increase microglial area in slices treated with 1-10 $\mu \mathrm{M}$ A740003 $(5.0 \pm 0.3 \%, n=6, p<0.05$ vs FGF- 1$)$ or $1-10 \mu \mathrm{M} \mathrm{BBG}(10.0 \pm$ $0.1 \%, n=6, p<0.05$ vs FGF-1) or $100 \mu \mathrm{M}{ }^{10} \mathrm{Panx} 1(9.2 \pm 4.1$, $n=6, p<0.05$ vs FGF-1). FGF-1 induced increase in microglial area was not significantly reduced by $1-10 \mu \mathrm{M}$ RB2 $(22.1 \pm 0.8$, $n=6, p>0.05$ vs FGF-1). The area of microglia in control slices was not significantly different from that in slices treated with the blockers alone ( $n=4, p>0.05$ vs control; for numerical values, see Fig. 10 legend). These data indicate that $\mathrm{P} 2 \mathrm{X}_{7} \mathrm{R}$ activation and Px1 HC opening mediate FGF-1-induced morphological activation of microglia (Px1 expression in microglia is unlikely to mediate these morphological responses because FGF-1 did not increase $\mathrm{Etd}^{+}$uptake in these cells; Fig. 6A).

To investigate whether FGF-1 is proinflammatory in spinal cord slices, we measured protein levels of proinflammatory cytokines, IL- $1 \beta$, IL- 6 , and TNF $\alpha$, by using ELISA in control or after treating spinal cord slices with FGF-1 for $1 \mathrm{~h}$ (Fig. $10 D-I)$. IL- $1 \beta$ and IL-6 protein levels were significantly increased after 1 h FGF- 1 treatment ( $p<0.05$ vs control, $n=5$ animals), whereas TNF $\alpha$ levels were not significantly changed compared with control slices $(p>0.05$ FGF- 1 vs control, $n=$ 5 animals). Elevation of IL- $1 \beta$ and IL- 6 levels was prevented by pretreatment of slices with $100 \mu \mathrm{M}{ }^{10} \mathrm{Panx} 1(p>0.05$ control $+{ }^{10}$ Panx 1 vs FGF- $1+{ }^{10}$ Panx, or $p<0.05$ FGF- 1 alone vs FGF- $1+{ }^{10}$ Panx, $n=4$ animals for IL- $1 \beta$ and IL-6, respectively; Fig. $10 D-F) .{ }^{10} \mathrm{Panx} 1$ was applied as in Figure $8 \mathrm{~A}$ and had no effect on control uptake.

In spinal cord slices depleted of microglia, the basal levels of IL- $1 \beta$, IL-6, and TNF $\alpha$ were significantly lower than in nonde- pleted cords $(p<0.05$ vs control nondepleted for IL- $1 \beta$, IL- 6 , and TNF $\alpha, n=6$ animals; Fig. $10 D-I$ ), indicating that, after acute tissue sectioning, microglia contribute to the basal production of proinflammatory cytokines. The decrease was much greater for TNF $\alpha$ than for IL- $1 \beta$ and IL- 6 . Consistent with the contribution of microglia in FGF-1-induced proinflammatory responses, FGF-1 treatment of slices depleted of microglia did not change levels of IL- $1 \beta$ ( $p>0.05$ vs control depleted, $n=6$ animals; Fig. $10 G)$. However, levels of IL-6 were significantly increased by FGF-1 treatment ( $p<0.05$ vs control depleted, $n=6$ animals; Fig. $10 H)$. The greatly reduced $\mathrm{TNF} \alpha$ levels in the depleted mice were not affected by FGF-1 treatment $(p>0.05$ vs control nondepleted, $n=5$ animals; Fig. $10 I$ ).

Spinal cord slices depleted of microglia and treated with ${ }^{10}$ Panx1 (100 $\left.\mu \mathrm{M}\right)$ showed similar levels of IL- $1 \beta$ in control and after FGF-1 treatment $(p>0.05$ ${ }^{10} \mathrm{Panx} 1$ alone vs FGF- $1+{ }^{10} \mathrm{Panx} 1, n=6$ animals). ${ }^{10}$ Panxl application to slices depleted of microglia increased the level of IL-6 $(p<0.05$, control depleted vs ${ }^{10} \mathrm{Panx} 1$ alone or $\left.{ }^{10} \mathrm{Panx} 1+\mathrm{FGF}-1\right)$, and these ${ }^{10} \mathrm{Panx} 1$-treated slices showed similar levels of IL- 6 in control and after FGF-1 treatment $\left(p>0.05,{ }^{10} \mathrm{Panx} 1\right.$ alone vs FGF- $1+{ }^{10} \mathrm{Panx} 1, n=6$ animals). These data indicate that microglia contribute to elevated IL- $1 \beta$ production after FGF-1 treatment (Fig. 10G-I), whereas FGF-1 increases IL-6 production in the absence of microglia, presumably by elevating astrocyte IL-6 production (Fig. $10 E, H)$.

Together, the data presented in this section suggest that FGF-1 is proinflammatory in ex vivo spinal cord slices by a process that involves Px1 HC opening in astrocytes.

\section{Discussion}

In this study, we report that FGF-1 mediates rapid opening of Px1 HCs in spinal astrocytes in both culture and acute spinal slices. This process depends on intracellular calcium signaling, ATP release, $\mathrm{P} 2 \mathrm{X}_{7} \mathrm{R}$ activation and opening of $\mathrm{Px} 1 \mathrm{HCs}$, and contributes to an inflammatory response in spinal cord slices.

Our data show that FGF-1 causes an increase in $\left[\mathrm{Ca}^{2+}\right]_{\mathrm{i}}$ that is blocked by a PLC inhibitor, suggesting that it is initiated by $\mathrm{IP}_{3}$ generation and $\mathrm{Ca}^{2+}$ release from the ER (Figs. 1, 3E, 11). The early rise in $\left[\mathrm{Ca}^{2+}\right]_{i}$ presumably mediates vesicular release of ATP, as the permeabilization induced by FGF-1 is blocked by botulinum toxin A (Garré et al., 2010) and by hydrolyzing extracellular ATP (Fig. $4 H$ ). The released ATP activates $\mathrm{P}_{2} \mathrm{X}_{7}$ Rs, which can be blocked by BBG and A740003 (two P2X $\mathrm{X}_{7} \mathrm{R}$ antagonists). Activation of $\mathrm{P} 2 \mathrm{X}_{7}$ Rs opens Px1 HCs that further enhance ATP release and mediate the subsequent plateau phase of elevated $\left[\mathrm{Ca}^{2+}\right]_{\mathrm{i}}$, which is associated with increased $\mathrm{Etd}^{+}$uptake. The contribution of $\mathrm{Px} 1$ to the plateau phase of $\left[\mathrm{Ca}^{2+}\right]_{\mathrm{i}}$ is indicated by the absence of this phase in cells transfected with siRNA Px1 (Figs. 1D,E, 2C,D).

In spinal astrocytes treated with ATP, P2X $\mathrm{X}_{7}$ Rs and Px1 HCs also contribute to increase $\left[\mathrm{Ca}^{2+}\right]_{\mathrm{i}}$ during the plateau phase (Fig. 2) (North, 2002; Sperlágh and Illes, 2014). 


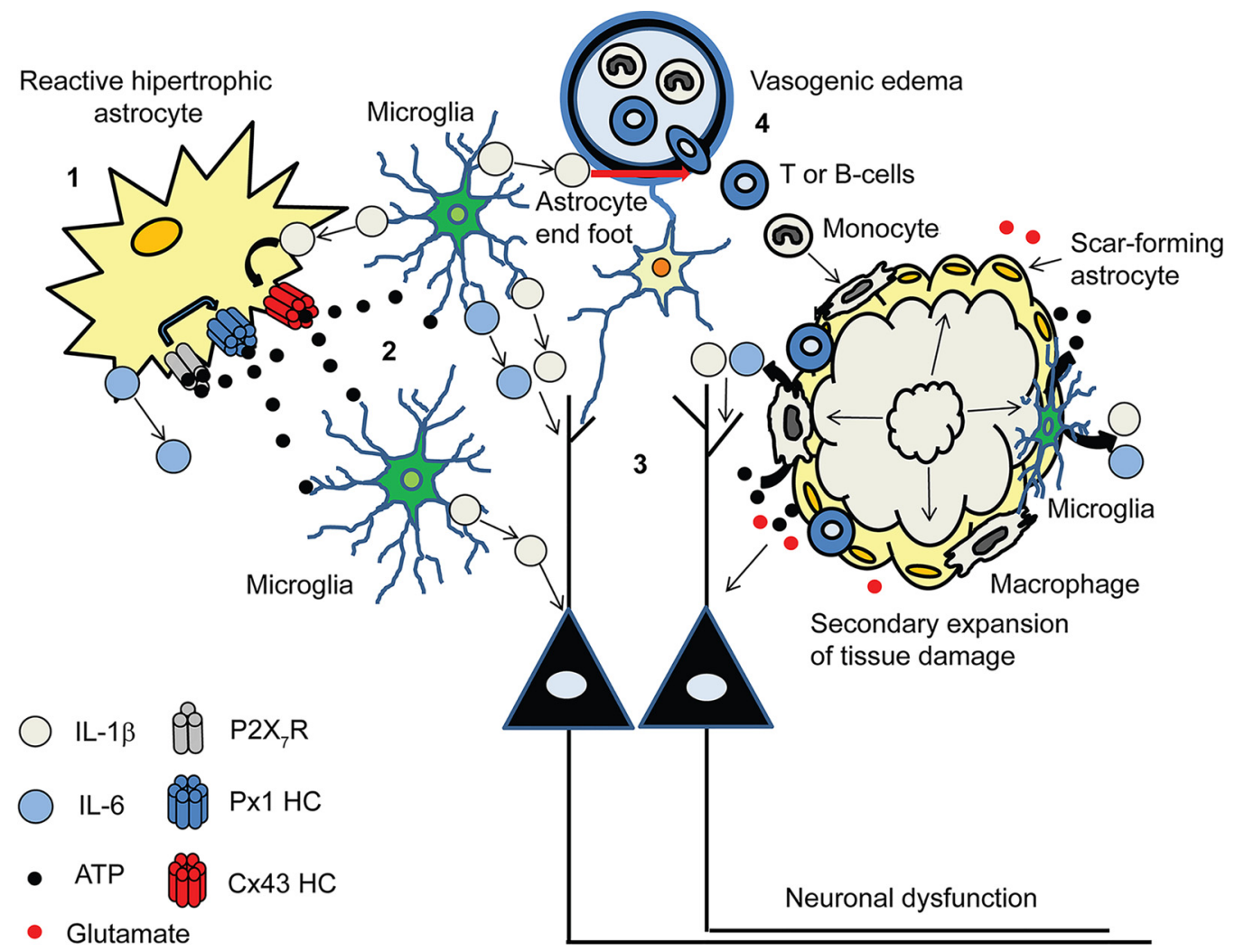

Figure 12. Possible mechanism whereby astrocyte responses to FGF-1 promote the transition from acute to chronic phases of spinal cord inflammation. 1, After $\sim 3$ h of the initial FGF-1 challenge (see Fig. 11), both Px1 HCs and Cx43 HCs in reactive astrocytes are open, and the self-sustained ATP release is established. 2, ATP stimulation maintains production of IL-1 $\beta$ by microglia and IL-6 by probably both astrocytes and microglia. 3, IL-1 $\beta$ has detrimental effects on neuronal structure and function. IL- $1 \beta$ may also promote opening of $\mathrm{Cx} 43 \mathrm{HCs}$ in astrocytes and contribute to sustained ATP release. IL-6 may have a dual role in spinal cord inflammation, preventing glutamate-mediated neurotoxicity, or being detrimental if its expression is uncontrolled. 4, Chronically, IL-1 $\beta$ causes vasogenic edema and breakdown of the blood-spinal cord barrier and favors recruitment into the spinal cord of bone marrow-derived immune cells (such as neutrophils, monocytes, and T cells). At the site of injury, released ATP and extracellular accumulation of glutamate may directly act as neurotoxic factors. Furthermore, a distinct population of astrocytes (scar-forming astrocytes), microglia/macrophages, and recruited immune cells promote and elevate the production of inflammatory mediators that regulate the expansion of tissue damage and further contribute to neuronal dysfunction. In summary, FGF-1-induced ATP release mediated by both Px1 and Cx43 HCs may play an important role regulating these inflammatory responses after spinal cord injury.

Px1 HC-mediated $\mathrm{Etd}^{+}$uptake and rise in $\left[\mathrm{Ca}^{2+}\right]_{\mathrm{i}}$ after FGF-1 treatment were reduced by the PLC blocker U73122 (Fig. $3 D, G, H$ ), indicating that PLC activation links FGFR signaling and $\left[\mathrm{Ca}^{2+}\right]_{\mathrm{i}}$-dependent permeabilization. Accordingly, FGF-1 induced opening of Px1 HCs was also prevented by BAPTA-AM (Fig. $3 B, F$ ).

A distinctive property of $\mathrm{P} 2 \mathrm{X}_{7} \mathrm{Rs}$ is the increase in membrane permeability to large organic molecules and dyes within seconds after ATP binds to the receptor (North, 2002; Khakh and North,

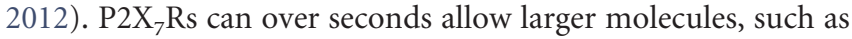
$\mathrm{Etd}^{+}$, to permeate, which was interpreted as a consequence of pore dilation by some workers (Yan et al., 2008; Browne et al., 2013). However, others have failed to see $P 2 X_{7} R$ pore dilation at the single-channel level (Riedel et al., 2007). An alternative mechanism to pore dilation was proposed to explain the observed changes in reversal potential in $\mathrm{P}_{2} \mathrm{X}_{2} \mathrm{Rs}$, namely, change in ion concentrations (Li et al., 2015). In our experiments, Etd $^{+}$uptake induced by FGF-1 or BzATP was blocked by siRNA knockdown of Px1 in cultured astrocytes, and FGF-1-induced Etd ${ }^{+}$uptake in cord slices (see below) was blocked by ${ }^{10} \mathrm{Panx} 1$; these data provide strong evidence that Px1 HCs mediate Etd ${ }^{+}$uptake in spinal astrocytes after $\mathrm{P}_{2} \mathrm{X}_{7} \mathrm{R}$ activation.

As FGF-1 action progresses, a nonvesicular mechanism contributes to ATP release (Garré et al., 2010), and changes in $\left[\mathrm{Ca}^{2+}\right]_{\mathrm{i}}$ are maintained. These processes may continue during 2-7 h of FGF-1 treatment (Fig. 5). Opening of both Px1 HCs
(Locovei et al., 2007) and subsequently Cx43 HCs (Kang et al., 2008) would tend to sustain ATP release and $\mathrm{Ca}^{2+}$.

In acute spinal cord slices, a more physiological preparation than astrocyte cultures, we found a population of astrocytes exhibiting enhanced Etd ${ }^{+}$uptake after 1 h FGF-1 treatment (Fig. 6). The primary cause of the enhanced uptake was the opening of Px1 HCs, as indicated by block by ${ }^{10} \mathrm{Panx} 1$ but not by Gap19, a selective blocker of Cx43 HCs (Abudara et al., 2014). FGF-1mediated opening of Px1 HCs in cord slices depends on pathways similar to those described in spinal astrocyte cultures (i.e., intracellular calcium signaling), ATP release, and activation of $\mathrm{P} 2 \mathrm{X}_{7} \mathrm{Rs}$. Calcium dependence was confirmed in experiments with the $\left[\mathrm{Ca}^{+2}\right]_{\mathrm{i}}$ chelator BAPTA-AM or with a PLC inhibitor (Fig. 7A). P2 $\mathrm{X}_{7}$ Rs are broadly expressed in the normal spinal cord, particularly in microglia and astrocytes (Cotrina and Nedergaard, 2009). Expression of $\mathrm{P} 2 \mathrm{X}_{7} \mathrm{Rs}$ in adult neurons in situ is more controversial (Oliveira et al., 2011; Yang et al., 2015). The FGF-1-induced increase in high $\mathrm{Etd}^{+}$astrocytes in ex vivo cords was reduced at potencies that were much greater for $\mathrm{A} 740003$ and $\mathrm{BBG}$ than for RB2, suggesting that, among $\mathrm{P} 2 \mathrm{XRs}, \mathrm{P} 2 \mathrm{X}_{7} \mathrm{R}$ is a primary contributor to the Etd ${ }^{+}$uptake. Furthermore, FGF-1induced $\mathrm{Etd}^{+}$uptake was also sensitive to $\mathrm{A} 740003$ and ${ }^{10} \mathrm{Panx} 1$ in spinal cord slices depleted of microglia, indicating that this uptake is mediated by $\mathrm{P} 2 \mathrm{X}_{7} \mathrm{Rs}$ and Px1 HCs expressed by astrocytes and not microglia. Additional studies will be required to determine whether ATP release from spinal neurons activates 
$\mathrm{P} 2 \mathrm{X}_{7} \mathrm{R}$ - and Px1 HC-mediated ATP release from astrocytes during inflammation, although this process may be more relevant under physiological conditions. In contrast, cortical astrocytes did not increase $\mathrm{Etd}^{+}$uptake in response to FGF-1, suggesting that the effect of FGF-1 may be specific to the spinal cord and relevant in spinal cord inflammation.

Microglia play an important role in regulating innate immune responses in CNS (Prinz and Priller, 2014). LPS-induced inflammatory responses of microglia cause $\mathrm{Cx} 43 \mathrm{HC}$ opening in astrocytes in acute hippocampal slices, and the effect of LPS is blocked by minocycline (Abudara et al., 2015). FGF-1-induced Px1 HC opening in spinal astrocytes does not require microglia (Fig. 7C), and further studies will determine whether proinflammatory cytokines released by microglia contribute to the delayed $\mathrm{Cx} 43 \mathrm{HC}$ opening. For instance, Px1 HC-mediated ATP release increases the production of IL-1 $\beta$ by microglia (Fig. 10) that hours later ( $\sim 3 \mathrm{~h}$ in slices, $\sim 24 \mathrm{~h}$ in cultures) opens $\mathrm{Cx} 43 \mathrm{HCs}$ in astrocytes (Retamal et al., 2007; Orellana et al., 2011; Abudara et al., 2015) that would sustain ATP release (Figs. 11, 12).

At least partial activation of microglia and astrocytes results from slice preparation (Brockhaus et al., 1996; Takano et al., 2014). Nevertheless, FGF-1 caused an increase in the area (of a $z$-axis projection) of microglia, a morphological criterion of activation (Fig. 10) (Yang et al., 2013; Eyo et al., 2015). This response was prevented by blocking Px1 HC-mediated ATP release with $\mathrm{P}_{2} \mathrm{X}_{7} \mathrm{R}$ antagonists and ${ }^{10} \mathrm{Panx} 1$. FGF-1-induced $\mathrm{Px} 1 \mathrm{HC}$ opening in astrocytes led to increased production of IL- $1 \beta$ and IL- 6 that were reduced by treatment of slices with ${ }^{10}$ Panx1. Furthermore, FGF-1 increased the production of IL-6 (but not IL$1 \beta$ ) in absence of microglia (Fig. 10).

There is evidence that IL- $1 \beta$ can be detrimental to the CNS. In cultured hippocampal neurons, IL-1 $\beta$ enhances NMDAmediated neurotoxicity (Viviani et al., 2003) and in vivo it has been shown to be the primary mediator of vasogenic edema in ischemic injury (Basu et al., 2005). Furthermore, IL-1 $\beta$ impairs neuronal signaling in vitro by suppressing BDNF-dependent synaptic plasticity (Tong et al., 2012) and, in vivo, may decrease formation of new dendritic spines induced by microglia-derived BDNF (Parkhurst et al., 2013). In contrast to IL-1 $\beta$, IL-6 may have a dual role in CNS, preventing tissue damage and protecting different populations of neurons against excitotoxicity, or being detrimental if chronically upregulated (Spooren et al., 2011).

Furthermore, extracellular accumulation of ATP and glutamate have been shown to act directly on neurons and decrease survival in vitro (Freitas-Andrade and Naus, 2015).

We expect that both Px1 HCs and Cx43 HCs expressed in astrocytes contribute to the FGF-1-induced responses in vivo, although the time course might differ from that in cultures or acute slices. Previous studies have shown that A740003 reduces tactile sensation during neuropathic chronic pain (DonnellyRoberts et al., 2009). Furthermore, $\mathrm{P}_{2} \mathrm{X}_{7}$ Rs contribute to the early inflammatory phase of the response to traumatic injury of the spinal cord (Wang et al., 2004). As shown here, activation of these receptors by ATP leads to opening of Px1 HCs and release of further ATP (e.g., Locovei et al., 2007; Suadicani et al., 2012). Moreover, ATP released through Px1 HCs can act as a "find me signal" that recruits phagocytes to apoptotic cells (Chekeni et al., 2010). Interestingly, Px1 KO mice exhibit delayed onset of clinical signs of EAE, although in this case a putative compensatory upregulation of $\mathrm{P} 2 \mathrm{X}_{7} \mathrm{Rs}$ is observed later in the disease (Lutz et al., 2013). Moreover, ATP release shortly after traumatic injury of the spinal cord is decreased in mice with conditional $\mathrm{KO}$ of $\mathrm{Cx} 43$ in astroctyes (Huang et al., 2012). However, it is not clear whether
$\mathrm{Cx} 43$ acts as HCs, GJ channels, or both in promoting ATP release, or whether Pxl expression is downregulated in these mice. ATP may directly activate microglia (Davalos et al., 2005; Kim and Dustin, 2006) or favor monocyte recruitment into the brain by inducing the release of chemo-attractant chemokines from astrocytes (Sofroniew, 2015) through $\mathrm{P} 2 \mathrm{X}_{7}$-dependent pathways (Tewari et al., 2015). Furthermore, ATP released through Px1 $\mathrm{HCs}$ in endothelial cells during vascular inflammation regulates the recruitment of leukocytes into inflamed tissues (Lohman et al., 2015).

In conclusion, FGF-1 initiates a regenerative process of ATP release, initially through calcium-dependent mechanisms and subsequently mediated by $\mathrm{P}_{2} \mathrm{X}_{7} \mathrm{Rs}$ and $\mathrm{Px} 1 \mathrm{HCs}$. As we showed earlier, $\mathrm{Cx} 43 \mathrm{HCs}$ can contribute later in the inflammatory process (Fig. 12). Responses of spinal astrocytes to FGF-1 can contribute to an inflammatory milieu that increases microglial responses and favors the recruitment of peripheral immune cells and impacts negatively on neuronal structure and function.

\section{References}

Abudara V, Bechberger J, Freitas-Andrade M, De Bock M, Wang N, Bultynck G, Naus CC, Leybaert L, Giaume C (2014) The connexin43 mimetic peptide Gap19 inhibits hemichannels without altering gap junctional communication in astrocytes. Front Cell Neurosci 8:306. CrossRef Medline

Abudara V, Roux L, Dallérac G, Matias I, Dulong J, Mothet JP, Rouach N, Giaume C (2015) Activated microglia impairs neuroglial interaction by opening Cx43 hemichannels in hippocampal astrocytes. Glia 63:795-811. CrossRef Medline

Basu A, Lazovic J, Krady JK, Mauger DT, Rothstein RP, Smith MB, Levison SW (2005) Interleukin-1 and the interleukin-1 type 1 receptor are essential for the progressive neurodegeneration that ensues subsequent to a mild hypoxic/ischemic injury. J Cereb Blood Flow Metab 25:17-29. CrossRef Medline

Bennett MV, Contreras JE, Bukauskas FF, Sáez JC (2003) New roles for astrocytes: gap junction hemichannels have something to communicate. Trends Neurosci 26:610-617. CrossRef Medline

Brockhaus J, Möller T, Kettenmann H (1996) Phagocytozing ameboid microglial cells studied in a mouse corpus callosum slice preparation. Glia 16:81-90. CrossRef Medline

Brown KJ, Hendry IA, Parish CR (1995) Acidic and basic fibroblast growth factor bind with differing affinity to the same heparin sulfate proteoglycan on BALB/c 3T3 cells: implications for potentiation of growth factor action by heparin. J Cell Biochem 58:6-14. CrossRef Medline

Browne LE, Compan V, Bragg L, North RA (2013) P2X7 receptor channels allow direct permeation of nanometer-sized dyes. J Neurosci 33:35573566. CrossRef Medline

Bruzzone R, Hormuzdi SG, Barbe MT, Herb A, Monyer H (2003) Pannexins, a family of gap junction proteins expressed in brain Proc Natl Acad Sci U S A 100:13644-13649.

Bruzzone R, Barbe MT, Jakob NJ, Monyer H (2005) Pharmacological properties of homomeric and heteromeric pannexin hemichannels expressed in Xenopus oocytes. J Neurochem 92:1033-1043. CrossRef Medline

Buch T, Heppner FL, Tertilt C, Heinen TJ, Kremer M, Wunderlich FT, Jung S, Waisman A (2005) A Cre-inducible diphtheria toxin receptor mediates cell lineage ablation after toxin administration. Nat Methods 2:419-426. CrossRef Medline

Bunney TD, Esposito D, Mas-Droux C, Lamber E, Baxendale RW, Martins M, Cole A, Svergun D, Driscoll PC, Katan M (2012) Structural and functional integration of the PLC $\gamma$ interaction domains critical for regulatory mechanisms and signaling deregulation. Structure 20:2062-2075. CrossRef Medline

Cassina P, Pehar M, Vargas MR, Castellanos R, Barbeito AG, Estévez AG, Thompson JA, Beckman JS, Barbeito L (2005) Astrocyte activation by fibroblast growth factor-1 and motor neuron apoptosis: implications for amyotrophic lateral sclerosis. J Neurochem 93:38-46. CrossRef Medline

Charles AC, Merrill JE, Dirksen ER, Sanderson MJ (1991) Intercellular signaling in glial cells: calcium waves and oscillations in response to mechanical stimulation and glutamate. Neuron 6:983-992. CrossRef Medline

Chekeni FB, Elliott MR, Sandilos JK, Walk SF, Kinchen JM, Lazarowski ER, 
Armstrong AJ, Penuela S, Laird DW, Salvesen GS, Isakson BE, Bayliss DA, Ravichandran KS (2010) Pannexin 1 channels mediate 'find-me' signal release and membrane permeability during apoptosis. Nature 467: 863-867. CrossRef Medline

Contreras JE, Sánchez HA, Eugenin EA, Speidel D, Theis M, Willecke K, Bukauskas FF, Bennett MV, Sáez JC (2002) Metabolic inhibition induces opening of unapposed connexin 43 gap junction hemichannels and reduces gap junctional communication in cortical astrocytes in culture. Proc Natl Acad Sci U S A 99:495-500. CrossRef Medline

Contreras JE, Sáez JC, Bukauskas FF, Bennett MV (2003) Gating and regulation of connexin 43 (Cx43) hemichannels. Proc Natl Acad Sci U S A 100:11388-11393. CrossRef Medline

Cornell-Bell AH, Finkbeiner SM, Cooper MS, Smith SJ (1990) Glutamate induces calcium waves in cultured astrocytes: long-range glial signaling. Science 247:470-473. CrossRef Medline

Cotrina ML, Nedergaard M (2009) Physiological and pathological functions of P2X7 receptor in the spinal cord. Purinergic Signal 5:223-232. CrossRef Medline

Davalos D, Grutzendler J, Yang G, Kim JV, Zuo Y, Jung S, Littman DR, Dustin ML, Gan WB (2005) ATP mediates rapid microglial response to local brain injury in vivo. Nat Neurosci 8:752-758. CrossRef Medline

Donnelly-Roberts DL, Namovic MT, Han P, Jarvis MF (2009) Mammalian P2X7 receptor pharmacology: comparison of recombinant mouse, rat and human P2X7 receptors Br J Pharmacol 157:1203-1214. CrossRef Medline

Eyo UB, Gu N, De S, Dong H, Richardson JR, Wu LJ (2015) Modulation of microglial process convergence toward neuronal dendrites by extracellular calcium. J Neurosci 35:2417-2422. CrossRef Medline

Fischer W, Nörenberg W, Franke H, Schaefer M, Illes P (2009) Increase of intracellular $\mathrm{Ca}^{2+}$ by P2Y but not P2X receptors in cultured cortical multipolar neurons of the rat. J Comp Neurol 516:343-359. CrossRef Medline

Freitas-Andrade M, Naus CC (2015) Astrocytes in neuroprotection and neurodegeneration: the role of connexin 43 and pannexin 1 . Neuroscience. Advance online publication. Retrieved Apr. 23, 2015. doi: 10.1016/ j.neuroscience.2015.04.035. CrossRef Medline

Garré JM, Retamal MA, Cassina P, Barbeito L, Bukauskas FF, Sáez JC, Bennett MV, Abudara V (2010) FGF-1 induces ATP release from spinal astrocytes in culture and opens pannexin and connexin hemichannels. Proc Natl Acad Sci U S A 107:22659-22664. CrossRef Medline

Guthrie PB, Knappenberger J, Segal M, Bennett MV, Charles AC, Kater SB (1999) ATP released from astrocytes mediates glial calcium waves. J Neurosci 19:520-528. Medline

Hassinger TD, Guthrie PB, Atkinson PB, Bennett MV, Kater SB (1996) An extracellular signaling component in propagation of astrocytic calcium waves. Proc Natl Acad Sci U S A 93:13268-13273. CrossRef Medline

Hong JH, Moon SJ, Byun HM, Kim MS, Jo H, Bae YS, Lee SI, Bootman MD, Roderick HL, Shin DM, Seo JT (2006) Critical role of phospholipase C gammal in the generation of $\mathrm{H} 2 \mathrm{O} 2$-evoked $\left[\mathrm{Ca}^{2+}\right] \mathrm{i}$ oscillations in cultured rat cortical astrocytes. J Biol Chem 281:13057-13067. CrossRef Medline

Honore P, Donnelly-Roberts D, Namovic MT, Hsieh G, Zhu CZ, Mikusa JP, Hernandez G, Zhong C, Gauvin DM, Chandran P, Harris R, Medrano AP, Carroll W, Marsh K, Sullivan JP, Faltynek CR, Jarvis MF (2006) A-740003 [N-(1-\{[(cyanoimino)(5-quinolinylamino) methyl]amino $\}$ 2,2-dimethylpropyl)-2-(3,4-dimethoxyphenyl)acetamide], a novel and selective P2X7 receptor antagonist, dose-dependently reduces neuropathic pain in the rat. J Pharmacol Exp Ther 319:1376-1385. CrossRef Medline

Huang C, Han X, Li X, Lam E, Peng W, Lou N, Torres A, Yang M, Garre JM, Tian GF, Bennett MV, Nedergaard M, Takano T (2012) Critical role of connexin 43 in secondary expansion of traumatic spinal cord injury. J Neurosci 32:3333-3338. CrossRef Medline

Ji RR, Berta T, Nedergaard M (2013) Glia and pain: is chronic pain a gliopathy? Pain 154 [Suppl]:S10-S28.

Jung S, Aliberti J, Graemmel P, Sunshine MJ, Kreutzberg GW, Sher A, Littman DR (2000) Analysis of fractalkine receptor CX(3)CR1 function by targeted deletion and green fluorescent protein reporter gene insertion. Mol Cell Biol 20:4106-4114. CrossRef Medline

Kang J, Kang N, Lovatt D, Torres A, Zhao Z, Lin J, Nedergaard M (2008) Connexin 43 hemichannels are permeable to ATP. J Neurosci 28:47024711. CrossRef Medline
Kang W, Balordi F, Su N, Chen L, Fishell G, Hébert JM (2014) Astrocyte activation is suppressed in both normal and injured brain by FGF signaling. Proc Natl Acad Sci U S A 111:2987-2995. CrossRef Medline

Khakh BS, North RA (2012) Neuromodulation by extracellular ATP and P2X receptors in the CNS. Neuron 76:51-69. CrossRef Medline

Khakh BS, Sofroniew MV (2015) Diversity of astrocyte functions and phenotypes in neural circuits. Nat Neurosci 18:942-952. CrossRef Medline

Kim JV, Dustin ML (2006) Innate response to focal necrotic injury inside the blood-brain barrier. J Immunol 177:5269-5277. CrossRef Medline

Lai CP, Bechberger JF, Thompson RJ, MacVicar BA, Bruzzone R, Naus CC (2007) Tumor-suppressive effects of pannexin 1 in C6 glioma cells. Cancer Res 67:1545-1554. CrossRef Medline

Lee J, Blaber M (2009) The interaction between thermodynamic stability and buried free cysteines in regulating the functional half-life of fibroblast growth factor-1. J Mol Biol 393:113-127. CrossRef Medline

Lee M, Kang Y, Suk K, Schwab C, Yu S, McGeer PL (2011) Acidic fibroblast growth factor (FGF) potentiates glial-mediated neurotoxicity by activating FGFR2 IIIb protein. J Biol Chem 286:41230-41245. CrossRef Medline

Li M, Toombes GE, Silberberg SD, Swartz KJ (2015) Physical basis of apparent pore dilation of ATP-activated P2X receptor channels. Nat Neurosci 18:1577-1583. CrossRef Medline

Locovei S, Bao L, Dahl G (2006) Pannexin 1 in erythrocytes: function without a gap. Proc Natl Acad Sci U S A 103:7655-7659. CrossRef Medline

Locovei S, Scemes E, Qiu F, Spray DC, Dahl G (2007) Pannexin1 is part of the pore forming unit of the $\mathrm{P} 2 \mathrm{X}(7)$ receptor death complex. FEBS Lett 581:483-488. CrossRef Medline

Lohman AW, Leskov IL, Butcher JT, Johnstone SR, Stokes TA, Begandt D, DeLalio LJ, Best AK, Penuela S, Leitinger N, Ravichandran KS, Stokes KY, Isakson BE (2015) Pannexin 1 channels regulate leukocyte emigration through the venous endothelium during acute inflammation. Nat Commun 6:7965. CrossRef Medline

Lutz SE, González-Fernández E, Ventura JC, Pérez-Samartín A, Tarassishin L, Negoro H, Patel NK, Suadicani SO, Lee SC, Matute C, Scemes E (2013) Contribution of pannexin1 to experimental autoimmune encephalomyelitis. PLoS One 8:e66657. CrossRef Medline

Morita M, Higuchi C, Moto T, Kozuka N, Susuki J, Itofusa R, Yamashita J, Kudo Y (2003) Dual regulation of calcium oscillation in astrocytes by growth factors and pro-inflammatory cytokines via the mitogenactivated protein kinase cascade. J Neurosci 23:10944-10952. Medline

Nedergaard M (1994) Direct signaling from astrocytes to neurons in cultures of mammalian brain cells. Science 263:1768-1771. CrossRef Medline

North RA (2002) Molecular physiology of P2X receptors. Physiol Rev 82: 1013-1067. CrossRef Medline

Oliveira JF, Riedel T, Leichsenring A, Heine C, Franke H, Krügel U, Nörenberg W, Illes P (2011) Rodent cortical astroglia express in situ functional P2X7 receptors sensing pathologically high ATP concentrations. Cereb Cortex 21:806-820. CrossRef Medline

Orellana JA, Shoji KF, Abudara V, Ezan P, Amigou E, Sáez PJ, Jiang JX, Naus CC, Sáez JC, Giaume C (2011) Amyloid $\beta$-induced death in neurons involves glial and neuronal hemichannels. J Neurosci 31:4962-4977. CrossRef Medline

Parkhurst CN, Yang G, Ninan I, Savas JN, Yates JR 3rd, Lafaille JJ, Hempstead BL, Littman DR, Gan WB (2013) Microglia promote learningdependent synapse formation through brain-derived neurotrophic factor. Cell 155:1596-1609. CrossRef Medline

Pelegrin P, Surprenant A (2006) Pannexin-1 mediates large pore formation and interleukin-1beta release by the ATP-gated $\mathrm{P} 2 \mathrm{X}_{7}$ receptor. EMBO J 25:5071-5082. CrossRef Medline

Prinz M, Priller J (2014) Microglia and brain macrophages in the molecular age: from origin to neuropsychiatric disease. Nat Rev Neurosci 15:300312. CrossRef Medline

Retamal MA, Froger N, Palacios-Prado N, Ezan P, Sáez PJ, Sáez JC, Giaume C (2007) Cx43 hemichannels and gap junction channels in astrocytes are regulated oppositely by proinflammatory cytokines released from activated microglia. J Neurosci 27:13781-13792. CrossRef Medline

Reuss B, von Bohlen und Halbach O (2003) Fibroblast growth factors and their receptors in the central nervous system. Cell Tissue Res 313: 139-157. CrossRef Medline

Riedel T, Schmalzing G, Markwardt F (2007) Influence of extracellular monovalent 
cations on pore and gating properties of $\mathrm{P} 2 \mathrm{X} 7$ receptor-operated single-channel currents. Biophys J 93:846-858. CrossRef Medline

Sahu G, Sukumaran S, Bera AK (2014) Pannexins form gap junctions with electrophysiological and pharmacological properties distinct from connexins. Sci Rep 4:4955. CrossRef Medline

Scemes E, Giaume C (2006) Astrocyte calcium waves: what they are and what they do. Glia 54:716-725. CrossRef Medline

Scemes E, Suadicani SO, Spray DC (2000) Intercellular communication in spinal cord astrocytes: fine tuning between gap junctions and P2 nucleotide receptors in calcium wave propagation. J Neurosci 20:1435-1445. Medline

Sofroniew MV (2015) Astrocyte barriers to neurotoxic inflammation. Nat Rev Neurosci 16:249-263. CrossRef Medline

Sperlágh B, Illes P (2014) P2X7 receptor: an emerging target in central nervous system diseases. Trends Pharmacol Sci 35:537-547. CrossRef Medline

Spooren A, Kolmus K, Laureys G, Clinckers R, De Keyser J, Haegeman G, Gerlo S (2011) Interleukin-6, a mental cytokine. Brain Res Rev 67: 157-183. CrossRef Medline

Suadicani SO, Iglesias R, Wang J, Dahl G, Spray DC, Scemes E (2012) ATP signaling is deficient in cultured pannexin1-null mouse astrocytes. Glia 60:1106-1116. CrossRef Medline

Takano T, He W, Han X, Wang F, Xu Q, Wang X, Oberheim Bush NA, Cruz N, Dienel GA, Nedergaard M (2014) Rapid manifestation of reactive astrogliosis in acute hippocampal brain slices. Glia 62:78-95. CrossRef Medline

Tashiro A, Goldberg J, Yuste R (2002) Calcium oscillations in neocortical astrocytes under epileptiform conditions. J Neurobiol 50:45-55. CrossRef Medline

Tewari M, Monika, Varghse RK, Menon M, Seth P (2015) Astrocytes mediate HIV-1 Tat-induced neuronal damage via ligand-gated ion channel P2X7R. J Neurochem 132:464-476. CrossRef Medline

Tong L, Prieto GA, Kramár EA, Smith ED, Cribbs DH, Lynch G, Cotman CW
(2012) Brain-derived neurotrophic factor-dependent synaptic plasticity is suppressed by interleukin- $1 \beta$ via p 38 mitogen-activated protein kinase. J Neurosci 32:17714-17724. CrossRef Medline

Venance L, Stella N, Glowinski J, Giaume C (1997) Mechanism involved in initiation and propagation of receptor-induced intercellular calcium signaling in cultured rat astrocytes. J Neurosci 17:1981-1992. Medline

Viviani B, Bartesaghi S, Gardoni F, Vezzani A, Behrens MM, Bartfai T, Binaglia M, Corsini E, Di Luca M, Galli CL, Marinovich M (2003) Interleukin- $1 \beta$ enhances NMDA receptor-mediated intracellular calcium increase through activation of the Src family of kinases. J Neurosci 23 : 8692-8700. Medline

Wang X, Arcuino G, Takano T, Lin J, Peng WG, Wan P, Li P, Xu Q, Liu QS, Goldman SA, Nedergaard M (2004) P2X7 receptor inhibition improves recovery after spinal cord injury. Nat Med 10:821-827. CrossRef Medline

Xia X, Babcock JP, Blaber SI, Harper KM, Blaber M (2012) Pharmacokinetic properties of 2nd-generation fibroblast growth factor-1 mutants for therapeutic application PLoS One 7:e48210. CrossRef

Yan Z, Li S, Liang Z, Tomić M, Stojilkovic SS (2008) The P2X7 receptor channel pore dilates under physiological ion conditions. J Gen Physiol 132:563-573. CrossRef Medline

Yang G, Parkhurst CN, Hayes S, Gan WB (2013) Peripheral elevation of TNF- $\alpha$ leads to early synaptic abnormalities in the mouse somatosensory cortex in experimental autoimmune encephalomyelitis. Proc Natl Acad Sci U S A 110:10306-10311. CrossRef Medline

Yang Y, Li H, Li TT, Luo H, Gu XY, Lü N, Ji RR, Zhang YQ (2015) Delayed activation of spinal microglia contributes to the maintenance of bone cancer pain in female Wistar rats via P2X7 receptor and IL-18. J Neurosci 35:7950-7963. CrossRef Medline

Zakrzewska M, Wiedlocha A, Szlachcic A, Krowarsch D, Otlewski J, Olsnes S (2009) Increased protein stability of FGF-1 can compensate for its reduced affinity for heparin. J Biol Chem 284:25388-25403. CrossRef Medline 